\title{
Eine RÖMISChe Silberkasserolle aus Wieselburg an der Erlauf, Niederösterreich, MIT EXKURSEN ZU FORM UND FUNKTION VON RÖMISCHEM SILBER- und Bronzegeschirr (Kelle-Sieb, Kasserolle) \\ Roman IGL, Wien
}

\section{Einleitung}

An dieser Stelle soll eine römische Silberkasserolle vorgestellt werden, die sich seit Jahrzehnten in Privatbesitz befindet, doch erst jetzt bekannt wurde (Abb. 2-10) ${ }^{1}$.

Eingangs werden Fundort und -umstände besprochen. Nach der formalen Beschreibung wird versucht, die Kasserolle chronologisch einzuordnen. Hier soll kurz der Forschungsstand zu Quellenlage und Formen von römischem Silbergeschirr allgemein skizziert werden.

Ein weiteres Kapitel ist den Inschriften und den damit verbundenen Fragestellungen gewidmet.

Es folgt ein Exkurs zur umstrittenen Funktion römischer Kasserollen, aber auch die Funktion von Griffschalen und Kelle/Sieb-Garnituren wird behandelt.

\section{Fundort}

Es handelt sich - wie so oft bei römischem Silber - um einen Streufund, der Finder ist bereits verstorben, eine exakte Lokalisierung der Fundstelle, die sich in der Umgebung der SG. Wieselburg an der Erlauf/Niederösterreich, OG. Marbach befindet, ist nicht mehr möglich (Abb. 1).

Eine Begehung der in Frage kommenden Zone, also der (weit verstreuten) Äcker, die sich damals im Besitz des Finders befanden, wurde dennoch vorgenommen. Diese liegen auf den Terrassen des Kleinen Erlauftales, die auch noch heute ideale Voraussetzungen für die Landwirtschaft bieten ${ }^{2}$.

Es konnte zwischen Marbach und dem Siedlungsrand des heutigen Wieselburg an einigen Stellen römische Keramik beobachtet werden. Man kann hier wohl mehrere römische Villen vermuten. Im heutigen Ortsgebiet von Wieselburg und in der unmittelbaren Umgebung, insbesondere im Großen Erlauftal (Purgstall), zeigt sich eine recht hohe Dichte an Fundstellen, die römisches Material hervorbrachten. Wichtig ist der Wieselburger Kirchhügel, nur wenige Kilometer Luftlinie entfernt vom Bereich der „Fundstelle“ der Kasserolle. In der Sakristeimauer befanden sich Frag-
1 Der Besitzer wollte ausdrücklich anonym bleiben, da er das Gefäß weiterhin bei sich zu Hause aufbewahrt. Möglicherweise gelingt ein Ankauf durch das Kunsthistorische Museum Wien. Dr. A. Distelberger entdeckte das Objekt im Rahmen einer Sichtung archäologischer Privatsammlungen und machte das Institut f. Urund Frühgeschichte darauf aufmerksam. Die vorliegende Arbeit stellt die gekürzte Form der Proseminararbeit des Verf. am Institut f. Ur- und Frühgeschichte dar, deren Betreuung Univ. Prof. Dr. H. Friesinger übernahm. Ihm, Dr. E. Weber und Dr. A. Stuppner sei für die unzähligen Hilfestellungen herzlicher Dank ausgespro- chen. Auch Dr. H. Ubl, Dr. K. Gschwantler, Mag.V. Freiberger und Dr. H. Kerchler standen mit Rat und Tat zur Seite, wofür ich sehr dankbar bin. Die Zeichnungen fertigte Nicola Math an.

2 Zur Ortsgeschichte von Marbach M. Eilenderger, H. Lejsek (Hrsg.), Marbacher Dorfchronik und Häuserbuch, 1999, 10 ff. Zur Besiedlungsgeschichte des Erlaufgebiets im Grunde noch immer aktuell St. Denk, Ur- und frühgeschichtliche Funde im Erlauf-Gebiet, Amstetten 1953, 64 ff. Unweit von Purgstall (GroBes Erlauftal) wurde jüngst ein größeres kaiserzeitliches Gräberfeld untersucht, dazu F. SAuER, Fundber. Österr. 39, $2000,36$. 


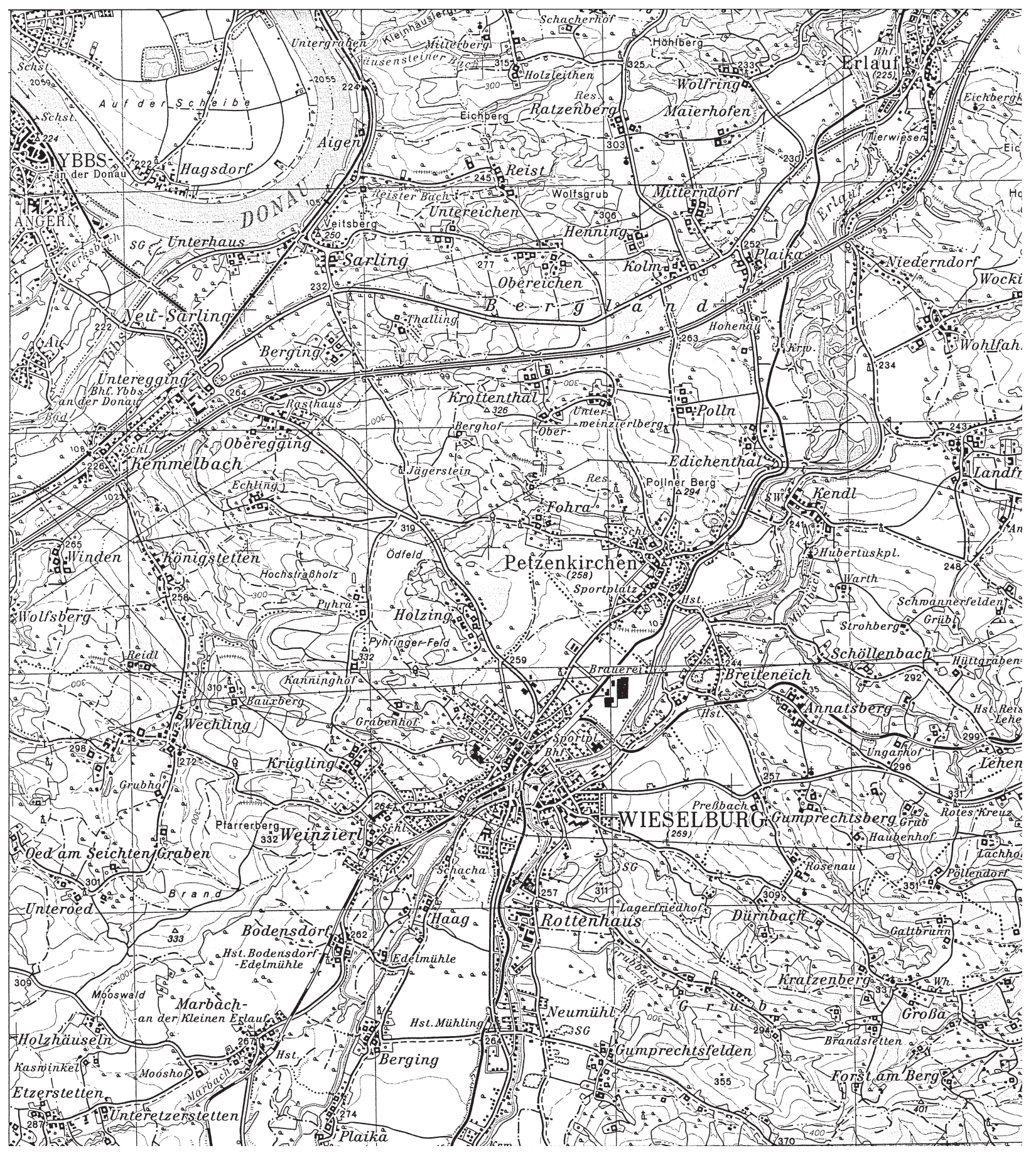

Abb. 1. ÖK 1:50.000 Ausschnitt aus Blatt 54, Melk, Bundesamt für Eich- und Vermessungswesen. 
mente eines großen Grabsteingiebels. St. Denk vermutet hier im Bereich der heutigen Kirche (mit dem prächtigen frühromanischen Zentralbau) einen römischen Grabbau ${ }^{3}$. Nur wenige Meter südöstlich der Kirche konnten Fundamentreste ergraben werden, die St. Denk als römischen Wachturm interpretiert.

Unweit von Wieselburg, bei Gumprechtsfelden, konnte H. Ladenbauer-Orel bei einer Notgrabung Gräber des 4.Jhs. bergen ${ }^{4}$. Bereits einige Kilometer flussaufwärts sind im Kleinen Erlauftal „Römersteine“ etwa in Pyhrafeld und Perwarth gefunden worden ${ }^{5}$. Römische Keramik und Kleinfunde hingegen wurden im Kleinen Erlauftal selten beobachtet, unsere Geländebegehung hat aber gezeigt, dass dies wohl forschungsbedingt zu erklären ist.

Zusammenfassend kann man zur Fundstelle der Kasserolle festhalten, dass sie im sanften Tal der Kleinen Erlauf mit großen Niederterrassen liegt. Mit römischer Siedlungstätigkeit ist hier durchaus zu rechnen.

\section{Beschreibung}

Gesamtlänge: 23,4 cm; Höhe 8,1 cm

Rand-Dm. außen: 13,1 cm; Rand-Dm. innen: 12,0 cm

Boden-Dm. außen: 8,1 cm; Boden-Dm. innen: 7,9 cm

Gewicht: $614 \mathrm{~g}$

Das Gefäß besitzt einen abgesetzten Randbereich, der nach innen hin verstärkt ist (Abb. 2-10). Der Rand ist im Verhältnis zur dünnen Gefäßwandung relativ dick ausgeführt. Hier setzt der flache Griff an. Die nur leicht geschwungene Wand ist außen mit einem Fries von 20 erhabenen Blättern verziert, der von zwei Perlenreihen gerahmt wird. Die Perlen, die an ihren Basen annähernd quadratisch sind, wurden in die Gefäßwand hineingeschnitten, ragen also nicht über diese hinaus. Die Wanddekoration ist im Vergleich mit der Griffzier relativ plastisch ausgeführt. Am flachen Boden belegen Zentrierpunkt und konzentrische Drehrillen, dass das Gefäß auf der Drehbank überarbeitet wurde. Wichtig ist der flache, an seinen Längsseiten leicht konkav eingezogene Griff. Er endet in der Form eines „Fischschwanzes“. Hier erkennt man zwei stark stilisierte Vogelköpfe, die sich mit den Hinterköpfen berühren (Abb. 6). Sie erscheinen nicht wie sonst üblich als plastisch gearbeitetes Relief, sondern bestehen aus feinen Rillen und punktförmigen Vertiefungen. Sowohl Körner als auch unterschiedliche Punzen kamen beim Eintiefen dieses Ornaments zum Einsatz.

Nach zwei volutenartigen und zwei kleinen, spitzen Verbreiterungen wird der Griffansatz fächerförmig erweitert (Abb. 2) und zwar in Form von zwei stark stilisierten Vogelköpfen, die sich an den Gefäßrand schmiegen. Die Voluten sind als stilisierte Rosetten zu verstehen. Die anschlieBenden Vogelköpfe sind auf dieser Kasserolle nur mehr in ihren Umrissen zu erahnen. Dies sei hier vorneweg bemerkt, wird aber erst bei der typologischen Einordnung von Bedeutung sein. Zwei feine Rillen verlaufen entlang des Randes der Handhabe, es sind keinerlei Reste von Nielloeinlage zu beobachten. Die auf der Griffoberseite befindliche Weihinschrift besteht aus drei Buchstaben I(ovi) O(ptimo) M(aximo), ihre Innenflächen sind mit größtenteils ausgefallener Goldfolie ausgelegt (Abb.4 und 9). Dazwischen liegen zwei kleine Dreiecke, auch sie zeigen Reste von Goldfolienbesatz. Die ohnehin hauchdünne Goldfolie ruht in den abgearbeiteten Silber-Betten, die Oberfläche bleibt somit vollkommen glatt. An der Griffunterseite sind punzierte Zeichen $\mathrm{zu}$ sehen, es handelt sich hierbei um eine Gewichtsangabe (Abb. 3, 5 und 10). Auch sie wird im Kapitel Inschriften genauer behandelt.

Die vom Pflug eingedellte Schale wurde vom Finder (glücklicherweise recht sorgsam) ausgehämmert. Abgesehen von kleineren Beschädigungen am Griffansatz (Riss), Griffende und der teilweise ausgefallenen Goldfolie der Inschrift auf der Griffoberseite, kann man den Erhaltungszustand der Kasserolle insgesamt als ausgezeichnet bezeichnen. Spuren verschiedener Herstellungs- und Nachbearbeitungstechniken finden sich an mehreren Stellen der Kasserolle ${ }^{6}$.

Es handelt sich um eine Gussarbeit, die auf der Drehbank überarbeitet wurde. Zentrierpunkt und Drehrillen belegen dies. An der Bodenunterseite kann man neben dem Zentrierpunkt einen zweiten erkennen. Hier wurde offensichtlich falsch angesetzt und korrigiert (Abb. 3).

Der Übergang vom Griff zum Schalenrand ist nicht sehr sauber ausgeführt. Möglicherweise ist der gesamte Griff überhaupt als eine spätere Zutat bzw. Reparatur zu betrachten, was auch die andersartige Zier erklären würde. Technisch ist dies nicht einwandfrei nachweisbar, da die Griffe ja meist angelötet wurden. Eine spätere Reparatur ließe ja
3 St. Denk, Das Erlaufgebiet in ur- und frühgeschichtlicher Zeit, Wien 1962, $181 \mathrm{ff}$

4 Denk, s. Anm. 3, $99 \mathrm{ff}$
5 Denk, s. Anm. 2, Abb. 35; 36.

6 Nach freundl. Auskunft von Mag.V. Freiberger, Kunsthistor. Mus. Wien. 

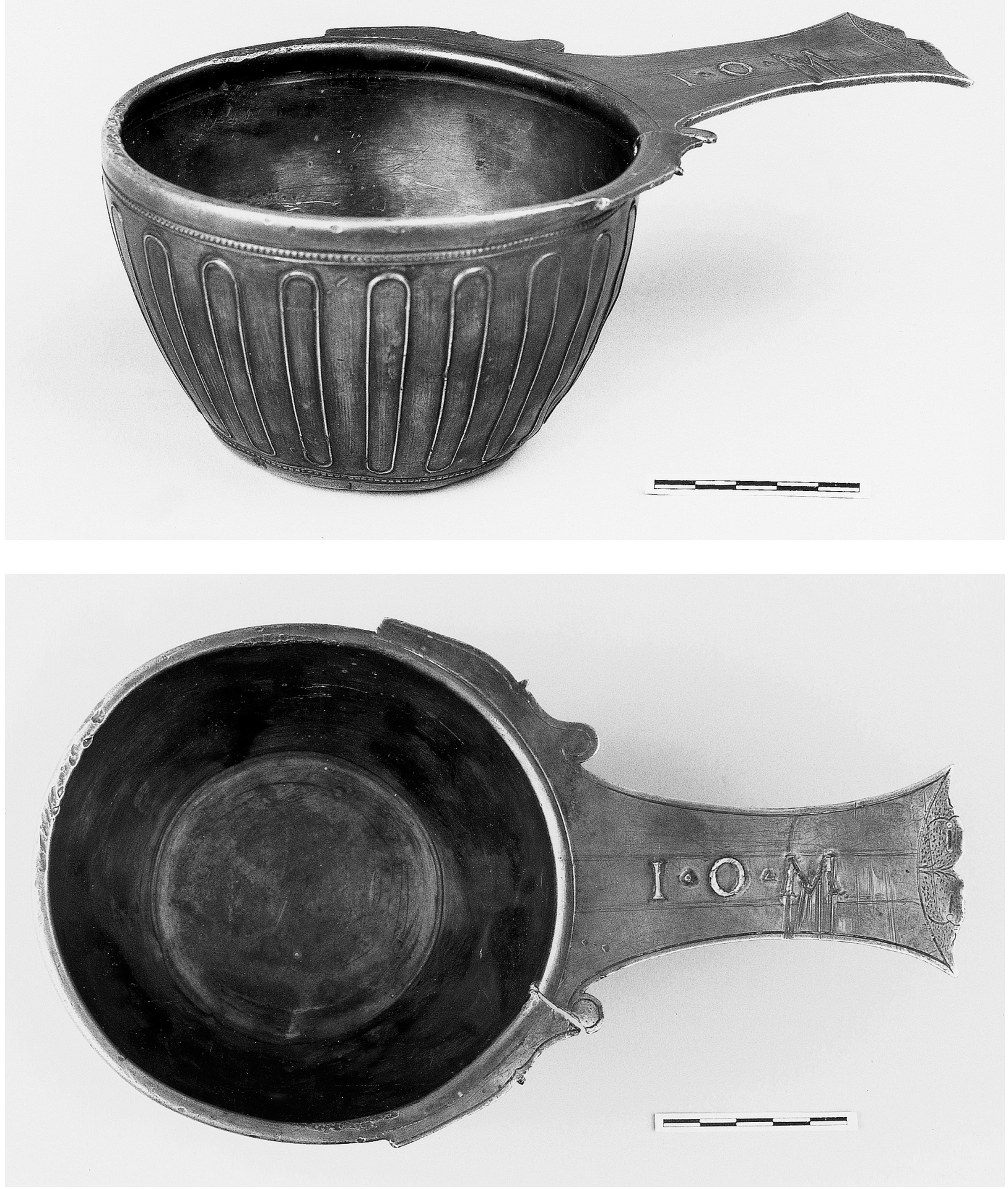

Abb. 2. Wieselburg, Silberkasserolle. Foto Inst. f. Ur- u. Frühgesch. Univ. Wien. 

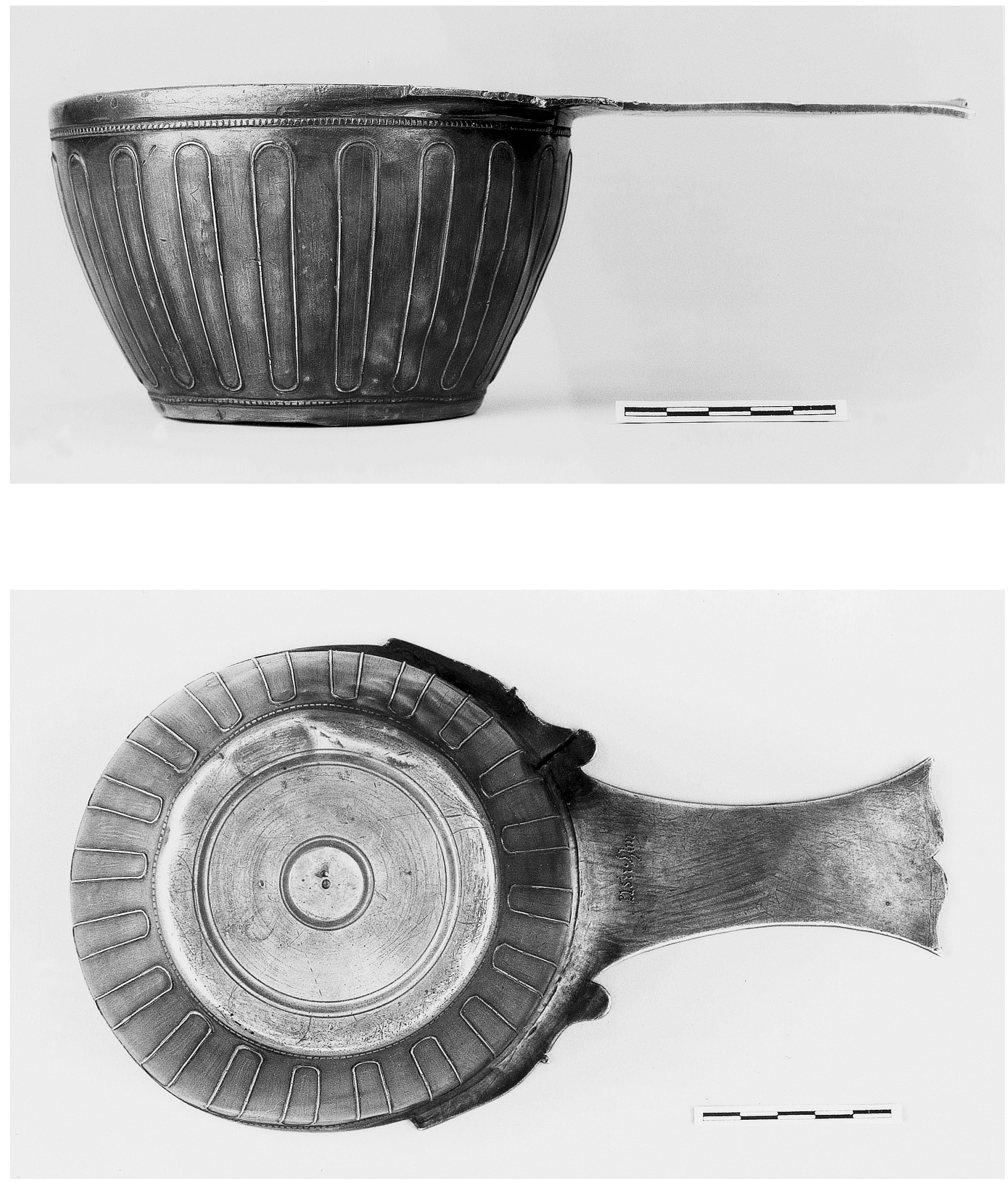

Abb. 3. Wieselburg, Silberkasserolle, Foto Inst. f. Ur- u. Frühgesch. Univ. Wien. 


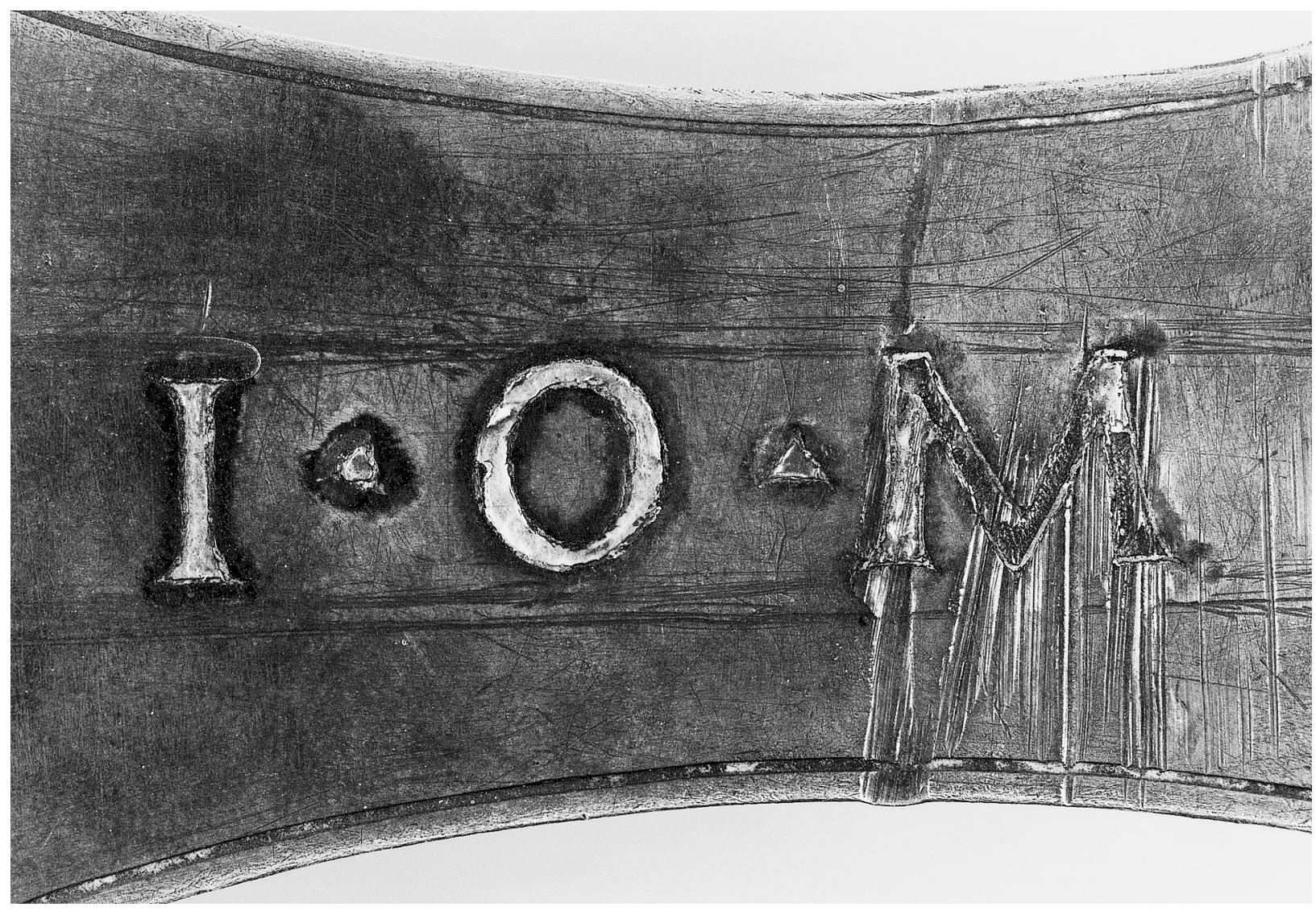

Abb. 4. Wieselburg, Silberkasserolle, Inschrift auf der Griffoberseite, Foto Inst. f. Ur- u. Frühgesch. Univ. Wien.

ebenfalls nur eine Lötstelle erkennen. Lötungen an römischen Silbergegenständen weisen oft einen so hohen Silberanteil auf, dass die Nähte mit freiem Auge kaum bis gar nicht erkennbar sind. Der Blattfries an der Außenwand der Schale wurde geschnitten, was vertikale Schaberrillen belegen. Die Perlenreihe scheint mit dem Stichel herausgearbeitet worden sein. Man hat bei diesen Techniken also Material abgehoben. Für die Buchstaben I O M arbeitete man etwas Material ab, die Fläche wurde aufgeraut, darauf wurde die Goldfolie gelegt. Die Außenkanten sind etwas unterschnitten, sodass man die Folie durch Einhämmern des Falzes fixieren konnte. Die meisten dieser feinen Arbeitsspuren sind mit freiem Auge kaum erkennbar.

Für den Silberschatz aus Kaiseraugst, der zwar wesentlich jünger ist als die hier behandelte Kasserolle, liegen sehr gute Analysen zur Herstellungstechnik vor ${ }^{7}$. Es treten Kom- binationen aus Gusstechnik im Wachsausschmelzverfahren und verschiedensten Treib- und Schnittechniken auf. Aufgrund der Vielfalt der in Frage kommenden Arbeitsmethoden ist die Rekonstruktion der Herstellungsverfahren solcher Silbergefäße ein ausgesprochen schwieriges Unterfangen.

\section{Römisches Silbergeschirr}

\section{Quellenlage}

Vor dem Versuch einer chronologischen Einordnung der vorliegenden Kasserolle muss hier kurz auf die methodischen Probleme bei der Auswertung dieser Fundgattung hingewiesen werden.
7 E. Foltz, Ch. Raub, Herstellungstechnik, in: H. A. Cahn, A. Kaufmann-Heinimann (Hrsg.), Der spätrömische Silberschatz von Kaiseraugst, Basler Beitr. z. Ur- u. Frühgesch. 9, 1984, 361 ff.
- Weiters A. Mutz, Die Kunst des Metalldrehens bei den Römern, Basel 1972. 


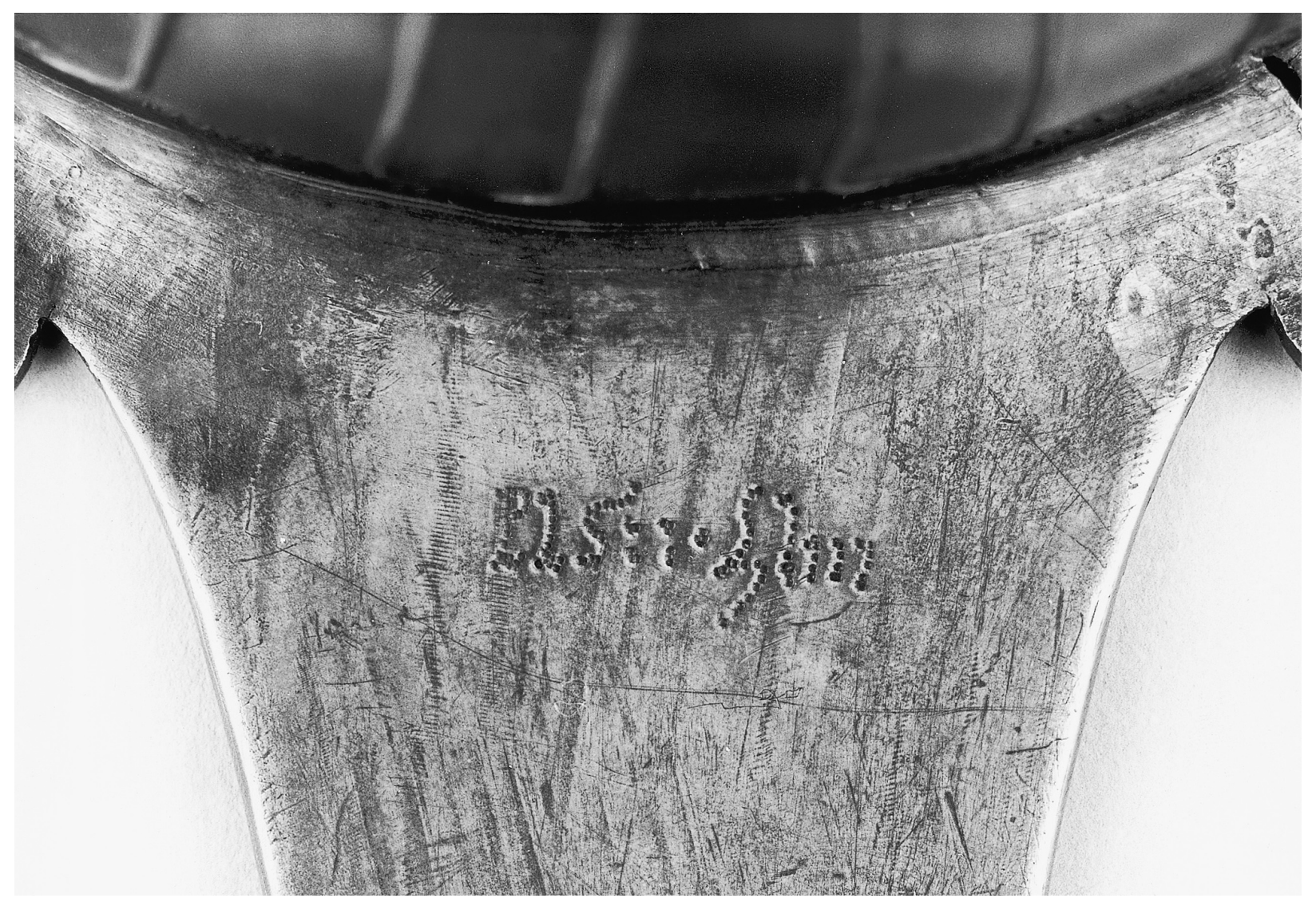

Abb. 5. Wieselburg, Silberkasserolle, Inschrift auf der Griffunterseite, Foto Inst. f. Ur- u. Frühgesch. Univ. Wien.

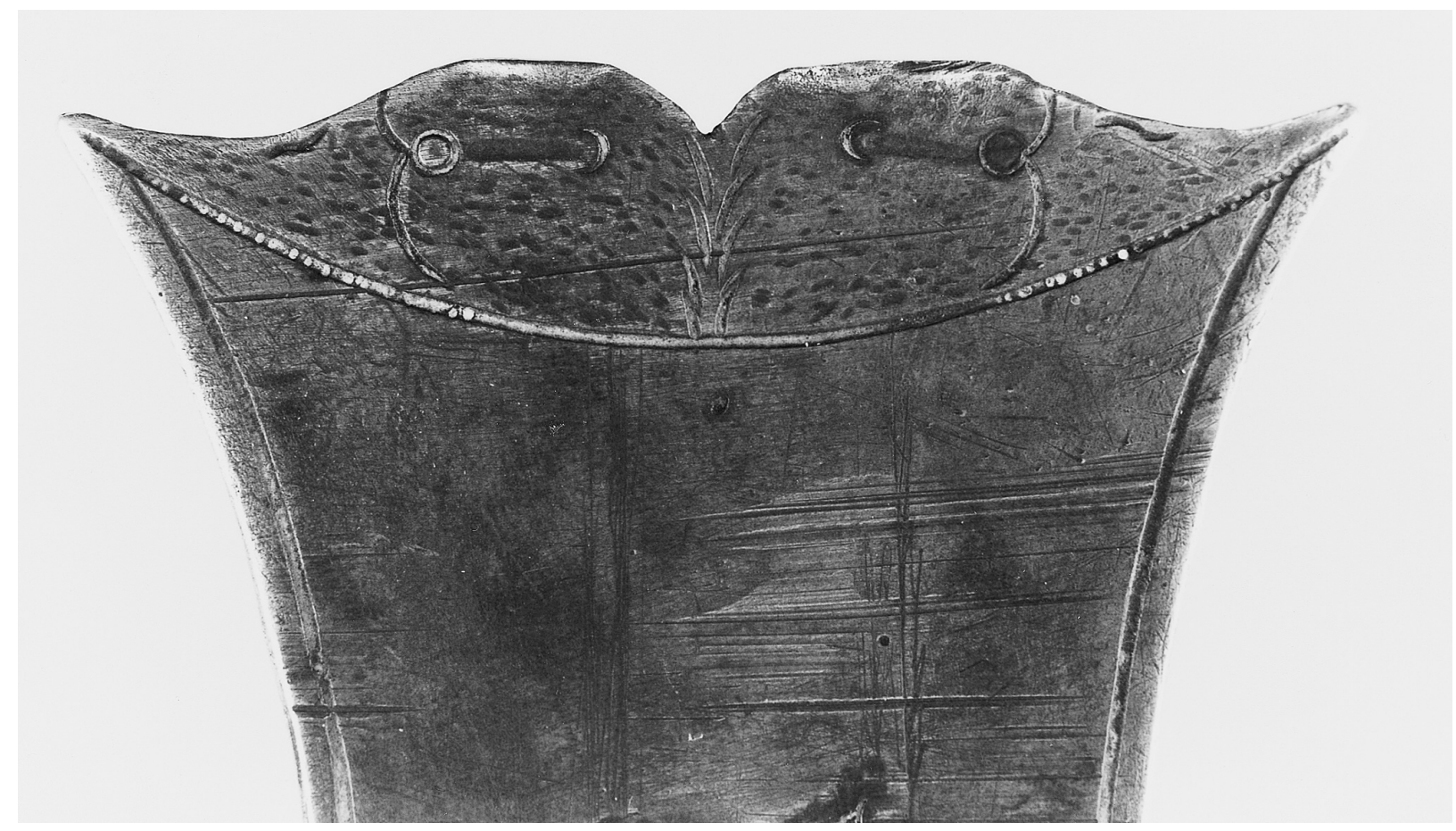

Abb. 6. Wieselburg, Silberkasserolle, Griffende, Foto Inst. f. Ur- u. Frühgesch. Univ. Wien. 

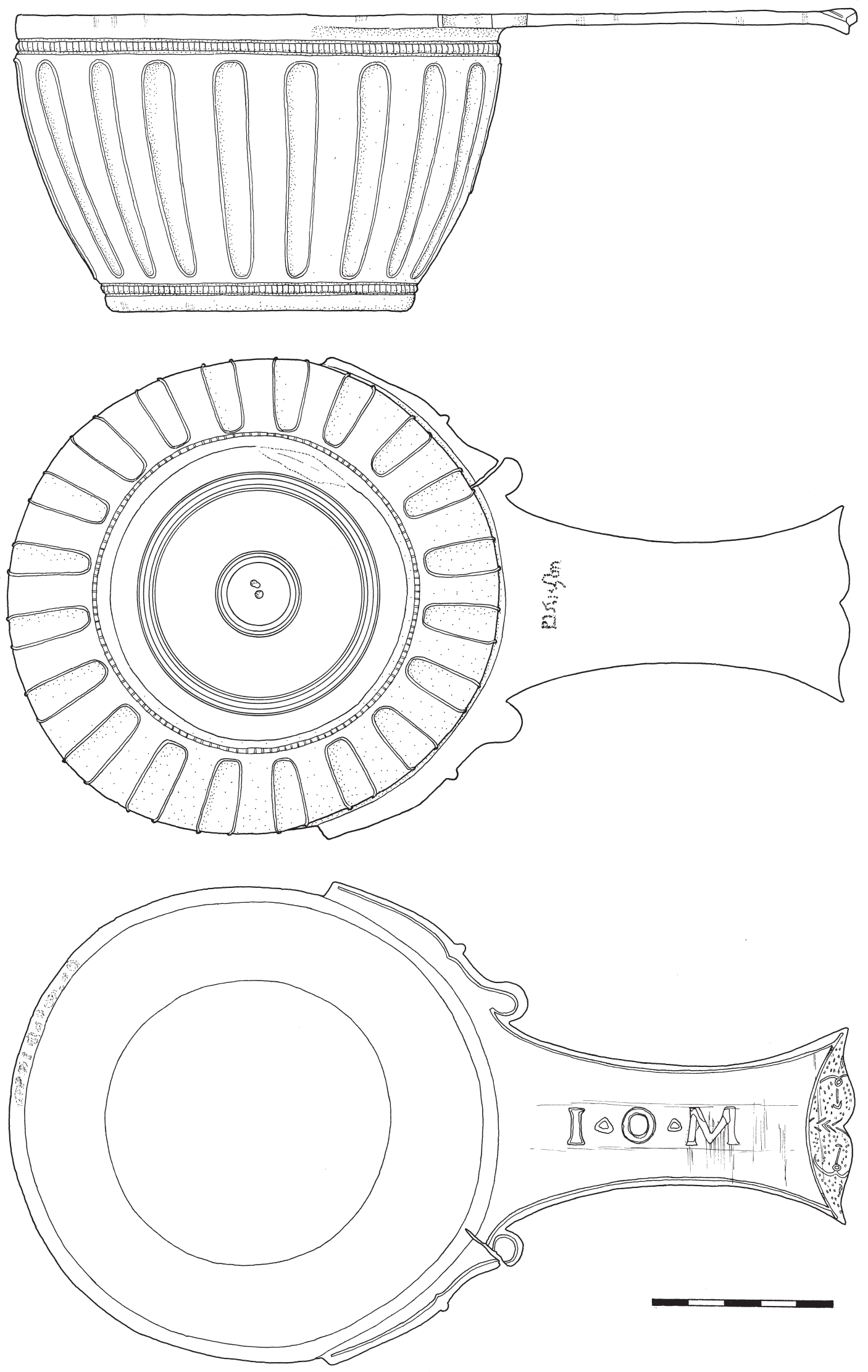

Abb. 7. Wieselburg, Silberkasserolle, Seitenansicht, Unteransicht, Draufsicht. 


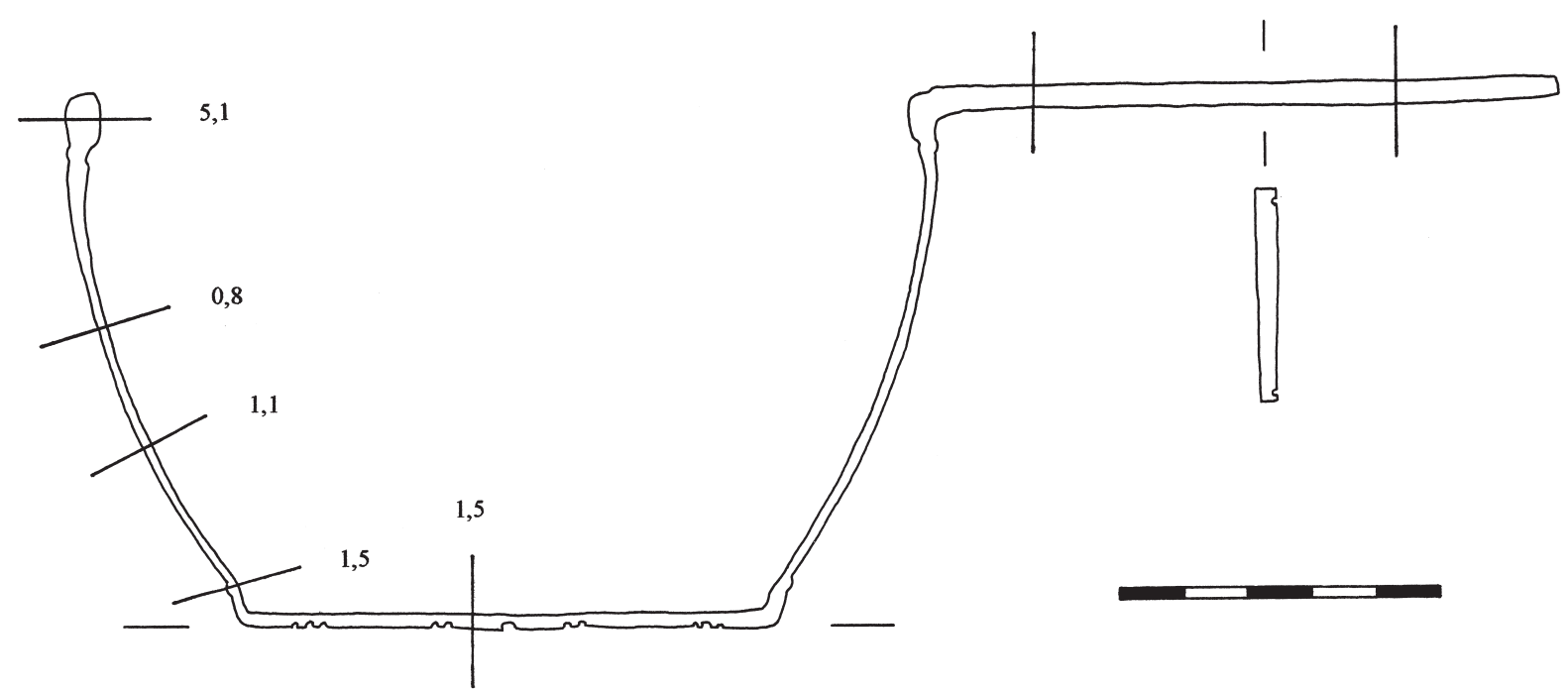

Abb. 8. Wieselburg, Silberkasserolle, Schnitt und Maße.

Die Quellenlage bei römischen Silbergefäßen ist problematisch ${ }^{8}$. Die Mehrzahl solcher auf ehemaligem Reichsboden gefundenen Objekte stammt aus Hortfunden. Weiters auch aus germanischen Grabfunden, wo sie aber oft als Altstücke vergesellschaftet sind. Viele Hortfunde wurden wegen ihres materiellen Werts zerstört. Der größte überlieferte Schatzfund römischer Silberobjekte mit einem Gesamtgewicht von $115 \mathrm{~kg}$ stammte aus Trier und wurde 1628 nach seiner Entdeckung eingeschmolzen ${ }^{9}$.

Der Großteil der Gefäße, die auf uns gekommen sind, stammt aus in Krisensituationen vergrabenen Horten ${ }^{10}$. Die Gattung des Hort-, Sammel- oder Depotfundes wird meist so definiert, dass hier Wertgegenstände vorliegen, die durch Verbergung im Boden fremdem Zugriff entzogen wurden.

Möglicherweise zählte auch die Kasserolle aus Wieselburg ursprünglich zu einem vergrabenen Hort. Sie kam ohne entsprechende Beifunde ans Tageslicht, diese sind möglicherweise schon früher durchs Ackern an die Oberfläche getreten und ,im Privatbesitz“ Dritter verschwunden, oder schlichtweg im Boden verblieben. E. Künzl betont ${ }^{11}$, dass kein römischer Tempelschatz vollständig auf uns ge-

8 Dazu zusammenfassend F. BARATTE, Römisches Silbergeschirr in den gallischen und germanischen Provinzen, Kl. Schr. z. Besetzungsgeschichte Südwestdeutschlands 32, 1984, 5 ff.

9 F. Baratte, Silbergeschirr, Kultur und Luxus in der römischen Gesellschaft, Trierer Winckelmannprogramme 15, 1997, 4.

10 Dazu allgemein Th. Fischer, Materialhorte des 3. Jhs. in den rö- kommen sei. Auf Neufunde sei kaum zu hoffen, da die christlichen Kaiser, insbesondere Theodosius, heidnische Tempel enteigneten. Es sei belegbar, dass in Tempeln auch Privatbesitz wie in einer Bank deponiert wurde. Als übergeordnete Kriterien, die Sakrales definieren, nennt E. Künzl: Inschrift (Götternamen, usw.), Form (etwa Votivbleche oder Kultsigna, also rein religiöse Zweckformen) und Fundort (selten nachgewiesen: Nähe zu Heiligtümern).

Silberkasserollen waren wohl beliebte Opfergaben, denn sie tragen häufig Weihinschriften bzw. Reliefs mit Darstellungen von Gottheiten und/oder deren Attributen.

Bei Objekten, die eindeutig Sakralcharakter aufweisen, müsse zwischen echten Votivfunden (etwa in Tempelarealen oder Quellheiligtümern) oder Vergrabungsdepots wie Angsthorten unterschieden werden. Bei den Horten aus Gewässern sei - E. Künzl folgend - oftmals schwer zu unterscheiden, ob es sich um echte Votivgaben oder doch eher um verlorene Objekte (besonders bei Waffen) handelt. Hortfunde der Art von Neupotz hingegen seien als Beutegut zu verstehen. Größere Metallgefäße sind als Wasserfunde selten, da sie wohl bereits in antiker Zeit wieder gehoben

mischen Grenzprovinzen zwischen Niedergermanien und Noricum, in: Das mitteleuropäische Barbaricum und die Krise des römischen Weltreiches im 3. Jh., Spisy Arch. Úst. AV ČR Brno 12, 1999, 19 ff.

11 E. KüNZL, Römische Tempelschätze und Sakralinventare. Votive, Horte, Beute, Antiquité Tardive 5, 1997, 57 ff. 

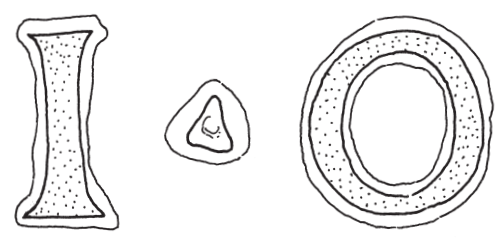

... Goldfolie

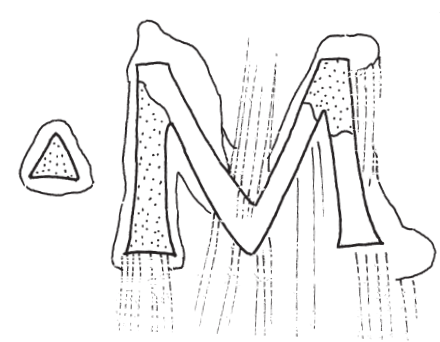

Abb. 9. Wieselburg, Silberkasserolle, Umzeichnung der Inschrift auf der Griffoberseite, vergrößert. wurden. Etwa eine Silberkasserolle aus der Rhône bei Tarascon mit Neptunusinschrift belege aber, dass auch solche Gefäße als Wasservotive geopfert wurden.

$\mathrm{Zu}$ den häufigsten Sakralkomplexen zählen die privaten Lararien, aber auch Dolichenus-Inventare.

E. Künzl untersuchte die Horte von Weissenburg, Straubing und Mauer an der Url. Hier wird die heterogene Zusammensetzung solcher Inventare betont. Besonders der hohe Anteil an Eisen spreche dafür, dass es sich beim Komplex von Weissenburg um zusammengeraubtes Plünderungsgut handelt. Der Hort von Mauer erscheint E. Künzl tatsächlich als Tempelinventar ${ }^{12}$. Alle drei Horte dürften in der ersten Hälfte des 3. Jh. vergraben worden sein.

E. Künzl stellt anhand von elf großen Sakralinventaren fest, dass sie nebst Münzen häufig Silbergefäße enthalten, während Schmuck, Waffen und Eisenobjekte hierbei selten vergesellschaftet sind. Danach wird anhand von Kartierungen gezeigt, dass Hortfunde besonders in den Nordwestprovinzen und zwar in Limesnähe im 2. und 3. Jh. auftreten, was im Zusammenhang mit den großen germanischen Invasionen gesehen werden dürfe. Horte aus dem 4. Jh. hingegen konzentrieren sich auf Britannien und den Bereich der unteren Donau.

Th. Fischer betont, dass Hortfunde, wenn sie flächig als „Horizont“ auftreten, eine tiefgreifende Störung der Siedlungskontinuität belegen ${ }^{13}$. Als Vergrabungsursachen unterscheidet Th. Fischer einerseits zwischen Funden, die vor einer drohenden Gefahr als Angsthorte vergraben wurden, und andererseits solchen, die Plünderer nach einer Katastrophe zusammengetragen haben. Angsthorte lassen sich daran erkennen, dass hier meist sinnvoll zusammengehörige, unbeschädigte Gegenstände enthalten sind. Je nach Zusammensetzung lassen sich in solchen Horten manchmal Tempelinventare, Inventare aus Waffenkammern, dem privaten Haushalt (Kücheninventar oder Werkzeuge), Fami- lienschätze mit Münzen oder Schmuck aber auch Materialdepots, etwa von Händlern/Handwerkern erkennen. Sie sind meist sorgfältig verpackt vergraben worden. Auch Brunnenhorte - oft als Votivdepots interpretiert - stellen wohl häufiger, als bisher vermutet, Angsthorte dar. Der Befund von Harting, wo Eisengerät in einen Brunnen geworfen wurde, zeigt, wie dramatisch die Lage war: Man hatte nicht einmal mehr die Zeit, das Material zu vergraben, kurz darauf wurden die Besitzer dann selbst als Massakeropfer in den Brunnen geworfen. Th. Fischer sondert als zweite Gruppe die Plünderungshorte ab, sie seien an ihrer sehr heterogen Zusammensetzung erkennbar. Sie enthalten oft (Eisen-)Schrott, der nach Brandkatastrophen gesammelt wurde.

Für die römische Kaiserzeit lasse sich besonders im 3. Jh. n. Chr. ein ausgeprägter „Depothorizont“ in den Nordwestprovinzen erkennen. Th. Fischer betont dabei den Zusammenhang mit massiven germanischen Überfällen und zeigt anhand der 149 behandelten Fundorte, dass mit ca. 56,4 \% die meisten Hortfunde aus den Bereichen Auxiliarlager mit ihren vici und villae stammen. Legionslager samt canabae hingegen lieferten nur 1,3\% der Hortfunde. In Gallien überwiegen Münzhorte, in Rätien sind Materialhorte besonders in Limesnähe stark konzentriert. Im östlichen Noricum sei eine Ausdünnung nach Osten hin zu bemerken. Dieses Bild erkennt man auch bei der Kartierung von Silber- und Bronzegefäßen. Zu den mittelkaiserzeitlichen Depotfunden in Noricum sei festzustellen, dass sie im Vergleich zu Rätien selten sind. Derartige Verwahrfunde liegen u.a. aus Wels, Mauer an der Url, Tittmoning, Wagna und auch aus Zell am See vor. Bei den Funden von Wels, Wagna und Zell am See dürfte es sich um vergrabenen Hausrat handeln, während Mauer an der Url als Tempelinventar gedeutet wird. Nebst Votivgaben weist Mauer an der Url auch etliche Kochgefäße auf. 
Die für die römischen Silbergefäße so wichtige Fundart der Hortfunde tritt in gewissen Zeitabschnitten massiert auf, wir kennen folglich nur einen Ausschnitt des Gesamtspektrums. Meist ohne archäologischen Befund ans Tageslicht gekommen, fehlen oft datierende Beifunde. Dazu kommt erschwerend der chronologische Unsicherheitsfaktor bezüglich der Laufzeiten. Die schlechte Datierbarkeit römischer Silbergefäße ist also quellenbedingt.

Germanische Grabfunde lieferten ebenfalls römische Silbergefäße in größerer Zahl. Auch hier muss die Problematik der Datierung angesprochen werden: Silberobjekte wurden meist als Altstücke beigegeben, wir stehen also erneut vor der Frage nach den Laufzeiten.

J. Wielowiejski behandelte u. a. die römischen Silberobjekte aus Polen ${ }^{14}$. Im Bereich der Przeworsk-Kultur finden sich echte Silberimporte, Nachahmungen und versilberte Bronzegefäße. Die Hälfte derartiger Gefäße Polens stammt aus reichen Gräbern vom Lübsow-Typ. Sie sind u. a. Ausdruck des florierenden Handels zwischen dem Imperium und dem germanischen Bereich ${ }^{15}$, sie datieren in die Stufe B, in A fehlen sie noch. Sind diese reichen LübsowGräber in der älteren Kaiserzeit besonders in Norddeutschland bis Polen und Dänemark verbreitet, so verschiebt sich der Schwerpunkt später nach Süden ${ }^{16}$. U. Lund-Hansen ergänzt, dass diesen Gräbern bezüglich ihrer reichen Importe römischer Bronze-, Silber- und Glasobjekte die jungkaiserzeitlichen Fürstengräber vom Typ Hassleben-Leuna entsprechen ${ }^{17}$. Auch hier sei mit langen Laufzeiten zu rechnen: „Einige Bronzegefäße... sind abgenutzt und zuweilen repariert; das deutet darauf hin, dass sie in unterschiedlichen Zusammenhängen benutzt wurden und nicht nur als Grabausstattung dienten."

Auch im Gebiet des heutigen Deutschland lieferten reiche germanische Grabfunde römische Silberkasserollen, beispielsweise die Altfunde von Marwedel. F. Laux setzt diese Bestattungen in die erste Hälfte bis Mitte des 2. Jhs. ${ }^{18}$.

Wichtig ist Grab II, eine Bestattung ohne Waffen; dafür sehen wir hier die Beigabe von Silbergeschirr und Glasbe-

14 J. Wielowiejski, Die römerzeitlichen Silbergefäße in Polen. Importe und Nachahmungen, Ber. Röm.-Germ. Komm. 70, 1990, 191 ff. - DERs., Chronologie und Zustrom von Bronzegefäßen aus der späten römischen Republik nach Mitteleuropa, Acta Arch. Carpathica 30, 1991, $141 \mathrm{ff}$.

15 E. KüNZL, Romanisierung am Rhein. Germanische Fürstengräber als Dokument des römischen Einflusses nach der gescheiterten Expansionspolitik, in: Kaiser Augustus und die verlorene Republik, Berlin 1988, 546 ff.

16 R. Stupperich, Römisches Silbergeschirr der mittleren bis späten Kaiserzeit in Germanien, in: Das Haus lacht vor Silber, Kat. d. Rhein. Landesmus. Bonn 8, 1997, 71 ff.

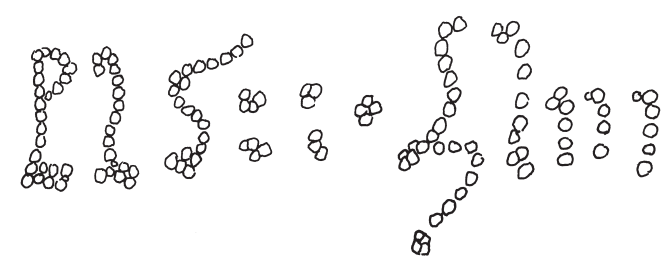

Abb. 10. Wieselburg, Silberkasserolle, Umzeichnung der Inschrift auf der Griffunterseite, vergrößert.

chern, weiters eine Kasserolle aus Bronze, Kelle und Sieb, ein Eimer und Trinkhornendbeschläge. Beim Silbergeschirr handelt es sich um zwei Kasserollen (Eggers 153) und zwei Becher (Eggers 174), deren Herstellung bereits in die erste Hälfte des 1. Jhs. zu setzen sei.

Eine ähnliche Situation sehen wir etwa beim Brandgrab von Groß-Kelle, Mecklenburg ${ }^{19}$. Die römischen Silberimporte sind auch hier eindeutig Altstücke. Bei der näheren Datierung von Silberkasserollen helfen diese Befunde also kaum weiter.

R. Stupperich fasst zusammen, auf welch unterschiedlichen Wegen römisches Silber ins freie Germanien gelangen konnte ${ }^{20}$ : Einerseits durch römische Truppen, die im Rahmen der Feldzüge bereits unter Augustus entsprechendes Material mitbrachten. Bald schon dürfte regelrechter Handel, insbesondere aber diplomatische Geschenke an die germanische Elite Silberobjekte in den germanischen Bereich und deren Gräber geführt haben. Auf kriegerischem Wege gelangten solche Stücke wohl erst vermehrt im 3. Jh. über den Limes. Besonders in spätrömischer Zeit wurden Silberobjekte zerschnitten und als Vorstufe zum Münzgeld im germanischen Bereich verwendet.

\section{Formen}

Betrachten wir kurz die wichtigsten Formen von römischem Silbergeschirr und deren grobe chronologische Entwicklung ${ }^{21}$. Silbergeschirr war während der gesamten römi-

17 U. Lund-Hansen, Römischer Import nach Norden, Nordiske Fortidsminder B 10, 1987, 196.

18 F. LAUx, Überlegungen zu den germanischen Fürstengräbern bei Marwedel, Gde. Hitzacker, Kr. Lüchow-Dannenberg, Ber. Röm.Germ. Komm. 73, 1992, 315 ff.

19 Stupperich, s. Anm. 16, 75 ff.

20 Stupperich, s. Anm. 16, 84.

21 S. Martin-Kilcher, Services de table en métal précieux du 1. au 5. siècle. In: F. Baratte, Tresors d'orfevvrerie gallo-romains, Paris 1989, 15 ff. 
schen Kaiserzeit Kennzeichen des hohen Standes, Symbol für Vermögen. Dieser Charakter als Wertgegenstand war für viele Silberobjekte wohl bereits in antiker Zeit verhängnisvoll, sie wurden eingeschmolzen.

Das Grundproblem der Schatzfunde besteht darin, dass sie oftmals nur als Teil eines Gesamtinventars vergraben wurden bzw. durch Fundumstände bedingt nur unvollständig auf uns gekommen sind. Wir wissen also nicht, woraus ein komplettes Service zusammengesetzt war. Das Tafelgeschirr aus dem Haus des Menander in Pompeji, insgesamt 118 Objekte, stellt das umfangreichste geschlossene Ensemble dar, das auf uns gekommen ist. Der Gebrauch von Tafelsilber wurde aus dem hellenistischen Osten übernommen. Frühe Formen finden wir im Schatz von Hildesheim ${ }^{22}$. Aber auch etwa in den Inventaren der Casa del Menandro ${ }^{23}$. Bei diesen frühen Formen des 1. Jh. n. Chr. sind insbesondere die Trinkbecher, hergestellt in Italien, reich reliefgeschmückt. Es ist ein gewisser horror vacui hinsichtlich der Verzierung zu beobachten. Zu den verschiedenen Becherformen kommen Kratere, aus denen Wein mit Schöpfern mit vertikalen Griffen geschöpft wurde.

Ist bei den Gefäßen des 1. Jh. n. Chr. reicher, plastischer Dekor vorhanden, so ist bereits ab dem 2. Jh. eine Tendenz zum sparsameren Einsatz von Reliefzier zu beobachten. Der Stil wird insgesamt flacher und tendiert zu geometrischen Formen.

Silberkasserollen im Speziellen treten nach S. Künzl gegen Ende des 1. Jh. v. Chr. auf und seien keine aus dem griechischen Kulturraum übernommene Form ${ }^{24}$. Die Stücke aus dem Hildesheimer Silberschatz, in augusteische Zeit datiert, zählen u.a. zu den ältesten bekannten Silberkasserollen. Um oder nach 100 n. Chr. treten erstmals konische Gefäßformen hinzu. Die Griffe der Kasserollen bleiben aber weiterhin die wesentlichen Dekorationsträger. An deren Enden finden sich ab dem späten 1. Jh. n. Chr. häufig gegengestellte Vogelköpfe, aber auch am Griffansatz werden Vogelköpfe, die sich an die Gefäßrundung anschmiegen, sehr beliebt. Diese werden später, im Laufe des 2. und 3. Jhs., auch abstrakt, oft nur noch in ihren Umrissen dargestellt.

Ab dem späten 1. Jh. n. Chr. hält S. Künzl die Existenz einer eigenständigen gallischen Produktion für sehr wahrscheinlich. Für die Silbergefäße des 2. und 3. Jh. könne man nur sehr vage Datierungen vornehmen. Das Problem ist $\mathrm{m}$. E. dabei, dass besonders ab der Mitte des 3. Jhs. der in den

22 KüNZL, s. Anm. 15

23 A. MAiuri, La Casa del Menandro e il suo tesoro di argenteria, 1932, 354ff, Taf. 49-51, Taf. 60.

24 S. KüNZL, Römisches Tafelsilber. Formen undVerwendung, in: Das Haus lacht vor Silber, s. Anm. 16, 11 ff.
Nordwestprovinzen weit verbreitete „Angstdepothorizont“ die meisten Objekte lieferte, wie eingangs besprochen. Nicht nur die Datierung von Silberobjekten dieser Zeit fällt schwer, es ist auch eine geänderte Tischsitte zu beobachten. So treten die im 1. Jh. so beliebten, reich reliefverzierten Becher allmählich in den Hintergrund und werden offenkundig von Glasbechern abgelöst. Die Reliefzier verflacht, häufig treten nun Nielloarbeiten auf. Bei den Gefäßformen selbst seien große runde Platten und ovale Tabletts beliebt, dazu treten Löffel, Kannen, Krüge und Kragenrandschüsseln.

Als Spätphase in der Entwicklung des Silbergeschirrs könne die Zeit nach den politischen und militärischen Wirren der Mitte des 3. Jhs. gelten, also die zweite Hälfte des 3. und das gesamte 4. Jh.. Silberne Platten und Löffel erfreuen sich großer Beliebtheit, auch Perlrandbecken. Als prominente Beispiele für diese spätantike Produktion könne man dabei den Schatz von Kaiseraugst (vergraben in der Mitte des 4. Jh.), die Funde von Mildenhall und vom Esquilin in Rom anführen. Nun finden sich auf Silbergefäßen häufig christliche Symbole, auch Inschriften, die ihnen diplomatisch-offiziellen Charakter verleihen. Silberkasserollen hingegen werden im 4. Jh. selten. Sehr vereinzelt treten sie aber im Osten auch noch im 7. Jh. auf ${ }^{25}$.

\section{Chronologische Einordnung der Kasserolle}

Die Suche nach Parallelen zum vorliegenden Stück ist schwierig, es existieren nur wenige Entsprechungen. Es scheint sich bei den relativ seltenen Silberkasserollen um Einzelanfertigungen zu handeln. Man könnte vermuten, dass die Kasserollen aus Ton und Bronze, die ja in größerer Anzahl auf uns gekommen sind, bessere Datierungsansätze liefern.

\section{Keramische Kasserollen}

Eine wichtige Arbeit liegt für Gallien vor ${ }^{26}$. H.Vertet behandelt dabei Fragmente von ursprünglich 39 keramischen Kasserollen mit reliefverzierten Griffen aus Lezoux. Auch hier treten fast regelmäßig Götterattribute bzw. Götterdarstellungen auf. Der Stil ist bereits flacher, nicht mehr so plastisch wie bei den älteren Bronzekasserollen. Die Griffenden sind meist geschwungen in Form von Fischschwän-

25 M. MAngo, Continuity of fourth/fifth century silver plate in the sixth/seventh centuries in the eastern empire, Antiquité Tardive 5, 1997, $83 \mathrm{ff}$.

26 H. Vertet, Manches de patères ornés en céramique de Lezoux, Gallia 30, 1972, 5 ff. 


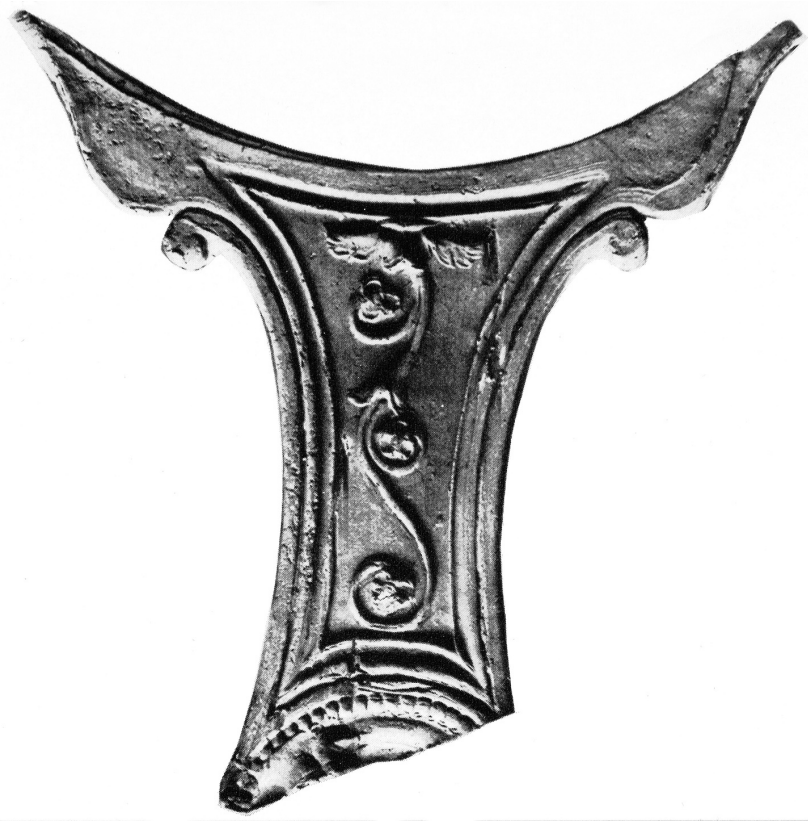

Abb. 11. Lezoux, Kasserollengriff, nach Vertet 1972, Taf. 6 (s. Anm. 26).

zen. An den Gefäßrändern befinden sich stark abstrahierte Vogelköpfe (Abb. 11). Von deren eigentlicher Physiognomie ist fast nichts mehr zu erkennen. Diese Stücke werden ins 2. Jh. datiert.

Jüngst wurden glasierte Kasserollengriffe aus Pannonien vorgelegt ${ }^{27}$. In unserem Zusammenhang ist das Stück aus Györ wichtig. Als Datierungsansatz wird das ersteViertel des 2. Jh. vorgeschlagen. Auch in der ,Wetterauer Ware“ kommen solche Kasserollen vor ${ }^{28}$. Diese Manufaktur nahm ihren Betrieb kurz vor 100 n. Chr. auf, das Produktionsende setzt V. Rupp bereits in die 30er Jahre des 2. Jh. n. Chr.. Insgesamt sei also eine Produktionsdauer von nur 30 bis 40 Jahren anzunehmen. Diese außergewöhnlich engen Schranken für die Datierung sind für uns von großer Bedeutung. Wir sehen dort, im ersten Drittel des 2. Jh. n. Chr., bereits stark stilisierte Vogelköpfe an den Griffoberseiten. Rudimentär angedeutete Drehrillen auf den Unterseiten der Böden sind zu beobachten, man imitierte offensichtlich Metallvorbilder. Sind somit (mit allen methodischen Vorbehalten) nicht auch

27 J. Topal, Glasierte Kasserollengriffe aus Pannonien, Acta Rei Cretariae Romanae Fautorum 34, 1995, 101 ff. - Wichtig dazu auch V. GASSNER, Mittelkaiserzeitliche glasierte Keramik aus Pannonien, Carnuntum Jahrb. 1991, 9 ff., Abb. 3

28 V. Rupp, Wetterauer Ware. Eine römische Keramik im RheinMain-Gebiet, Schr. d. Frankfurter Mus. f. Vor- u. Frühgesch. 10, 1988, 40 ff., F13 f3 und j1.
Rückschlüsse auf eine grobe Datierung der Metall-Vorbilder denkbar? Metallkasserollen werden schon in der zweiten Hälfte des 1. Jh. bei der Sigillata der Graufenesque-Ware imitiert $^{29}$, sie werden im gesamten 2. Jh. produziert. Einige Fragmente solcher frühen, reliefverzierten Sigillata-Kasserollen der zweiten Hälfte des 1. Jh. weisen die für diese Zeit noch so typisch plastische Reliefzier auf den Griffen auf. Auch die Sigillaten helfen bei der näheren Datierung von Silberkasserollen im Grunde kaum weiter.

\section{Bronzekasserollen}

Gleich vorab ist festzustellen, dass der Variationsreichtum der Silberkasserollen bezüglich Form und Dekor eine typologische Gliederung, wie wir sie für die Stücke aus Bronze kennen, kaum zulässt ${ }^{30}$.

A. Radnoti gliederte erstmals die Bronzekasserollen Pannoniens nicht nur nach formenkundlich-typologischen, sondern auch nach herstellungstechnischen Kriterien ${ }^{31}$. Wenn auch A. Radnotis Arbeit modifiziert wurde, so dient sie bis heute als Grundlage vieler typologischer Arbeiten zu römischen Bronzegefäßen. Zu den ältesten seien „flache Kasserollen mit langem Griff“ des 1. Jh. v. Chr. zu zählen. Dass am Anfang der Entwicklung von Kasserollen solche pfannenartigen, flachen Formen standen, gilt bis heute und ist m. E. ein wesentliches Kriterium bezüglich ihrer Funktion. Darauf wird unten einzugehen sein. Bei der Gruppe der „Kasserollen mit Schwanenkopfbügel“ mit Vogelkopfmotiv am Griffende verweist A. Radnoti auf hellenistische Vorbilder, sie sollen bereits in den letzten Jahrzehnten v. Chr. im süditalischen Bereich produziert worden sein.

„Kasserollen mit Scheibengriff, mit rundem Ausschnitt auf der Griffscheibe“ stellen die häufigste Kasserollenform im römischen Reich dar, sie sind aber auch häufig als Import im germanischen Bereich anzutreffen. Ihre Laufzeit reicht nach A. Radnoti von Christi Geburt bis ins 3. Jh. n. Chr..

Aktuelle und umfangreiche Materialvorlagen römischer Bronzegefäße stammen u. a. von S. Tassinari und R. Petrovsky ${ }^{32}$. R. Petrovsky unterscheidet bei den gestempelten Gefäßen 20 Haupttypen, die zusammen mit deren Varianten 66 Typen ergeben. Hier sind „Kasserollen mit reliefverziertem Griff (Typ VII)“ wichtig.

29 Etwa R. Lauxrois, A. Vernet, Patères à manche orné en céramique de la Graufenesque, Figlina 2, 1977, $13 \mathrm{ff}$.

30 Stupperich, s. Anm. 16, $74 \mathrm{ff}$.

31 A. Radnóti, Die römischen Bronzegefäße von Pannonien, Diss. Pann., Ser. 2, 6 1938, 9 ff.

32 S. TAssinari, Il vasellame bronzeo di Pompei, Rom 1993. - R. Petrovsky, Studien zu römischen Bronzegefäßen mit Meisterstempeln, Kölner Stud. Arch. Röm. Prov. 1, 1993. 

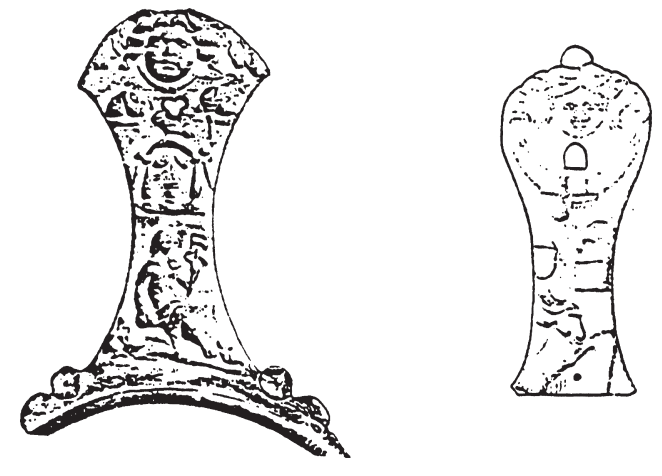

Er nimmt für diesen Typ (Abb. 12) eine Laufzeit von ca. 55/70 - 100/120 n. Chr. an ${ }^{33}$. Es liegen hierfur (wie ja auch bei den Silberkasserollen) meist nur Einzelfunde ohne datierende Beifunde vor. Als Herstellungsgebiet sei Gallien anzunehmen, dort liege auch der Verbreitungsschwerpunkt dieser Form ${ }^{34}$. S. Tassinari publizierte 31 griffverzierte, teils fragmentierte Bronzekasserollen ${ }^{35}$. Die Fundorte konzentrieren sich auf den gallischen Bereich, aber auch etwa aus Augsburg stammt eines der behandelten Stücke. Am Griffansatz und/oder Griffende treten Vogelköpfe auf, die als Standardzier unabhängig von den sonstigen Götterattributen auf vielen Kasserollengriffen vorkommen. Auch bei S. Tassinari werden die Schwierigkeiten der näheren Datierung unterstrichen.

Zusammenfassend muß man feststellen, dass unser Gefäß aus Wieselburg mit der flach gearbeiteten Vogelkopfzier samt Weihinschrift auf der Griffoberseite keine guten Entsprechungen im Bestand der Bronzekasserollen findet.

\section{Silberkasserollen}

Die Typologien der Bronzekasserollen lassen sich offensichtlich nicht direkt auf die aus Silber übertragen ${ }^{36}$. D. E. Strong schlug eine grobe typologische Gliederung von Silberkasserollen vor ${ }^{37}$. Das von ihm erstellte chronologische Gerüst

33 Petrovsky, s. Anm. 32, 89 ff.

34 Lund-Hansen, s. Anm. 17, 152 ff. betonte noch, dass insbesondere aufgrund der zu geringen Anzahl an Metallanalysen kaum zwischen gallischer und italischer Produktion unterschieden werden könne.

TASSINARI, Patères à manche orné, Gallia 28, 1970, 127 ff.

36 Stupperich, s. Anm. 16, 74 ff. formuliert sehr prägnant: „Silberkasserollen haben sicher die Formgebung der typologisch recht einheitlichen Bronzekasserollen beeinflusst, sind aber selbst viel freier... das gerundete Griffende ist oft mit einer Maske zwischen zwei Vogelköpfen verziert (Eggers Typ 152). Bei Bronzekasserollen

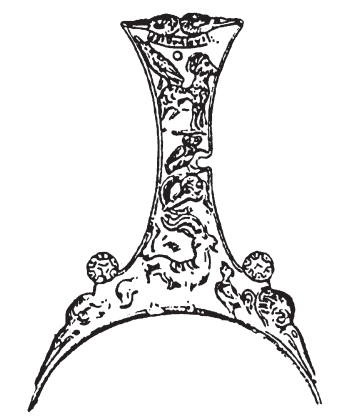

Abb. 12. Bronzekasserollen, Typ 7 nach Petrovsky 1993, Taf. 3 (s. Anm. 32).

vom 1. bis 4. Jh. n. Chr. ist bis heute Grundlage vieler Publikationen (Abb. 13). An der schlechten Datierbarkeit der Silberkasserollen hat sich bis heute fast nichts geändert. Schwanenköpfe an Griffansatz und -ende kommen demzufolge bereits auf Kasserollengriffen des 1. Jh. n.Chr. vor. Hinter diesen Köpfen treten wie bei Bronzekasserollen mit Reliefzier oft Rosetten auf, auch auf unserer Kasserolle sehen wir diese (wenn auch nur mehr abstrakt, auf ihre Umrisse reduziert). Für die Kasserollen mit geschwungenen Griffenden nimmt D. E. Strong Laufzeiten im gesamten 2. und 3. Jh. an. Das Stück aus Cullera (Abb. 13k) wird ins 3. Jh. datiert ${ }^{38}$. Allgemein wird die Reliefzier nun meist auf die Darstellung einer Figur (Gottheit) reduziert. Silberkasserollen werden dann im 4. Jh. n. Chr. selten.

Anhand der Gefäßform der meist unverzierten und wenig profilierten, einfachen Schalen lässt sich m. E. kaum eine formtypologische Entwicklung erkennen. Vielmehr sind es also die Griffe, die einerseits in der Grundform andererseits im Stil ihrer Zier Veränderungen unterworfen sind. Auf der Suche nach Parallelen muss deshalb besonderes Augenmerk auf die Griffgestaltung gelegt werden.

Noch seltener sind Silberkasserollen, bei denen statt Abbildungen von Göttern oder ihrer Attribute auf den Griffen in großen Buchstaben ausgeführte Weihinschriften auftreten. Das Vogelkopfmotiv an Griffende und -ansatz erscheint dennoch zusätzlich.

ist das selten. Den geraden Abschluss (Eggers Typ 153) bilden meist zwei sich mit den Hinterköpfen berührende Schwanenköpfe. Die Griffläche besteht in der Regel aus assoziativ zusammengestellten Einzelmotiven..., Figuren, die auf verschiedene Götter hinweisen...".

37 D. E. Strong, Greek and Roman Gold and Silver Plate, London 1966, 161 ff. - H.-J. EgGers, Der römische Import im freien Germanien, Atlas zur Urgeschichte, Hamburg 1959. Er arbeitete drei Typen von Silberkasserollen heraus.

38 Strong, s. Anm. 37, 169 ff. 

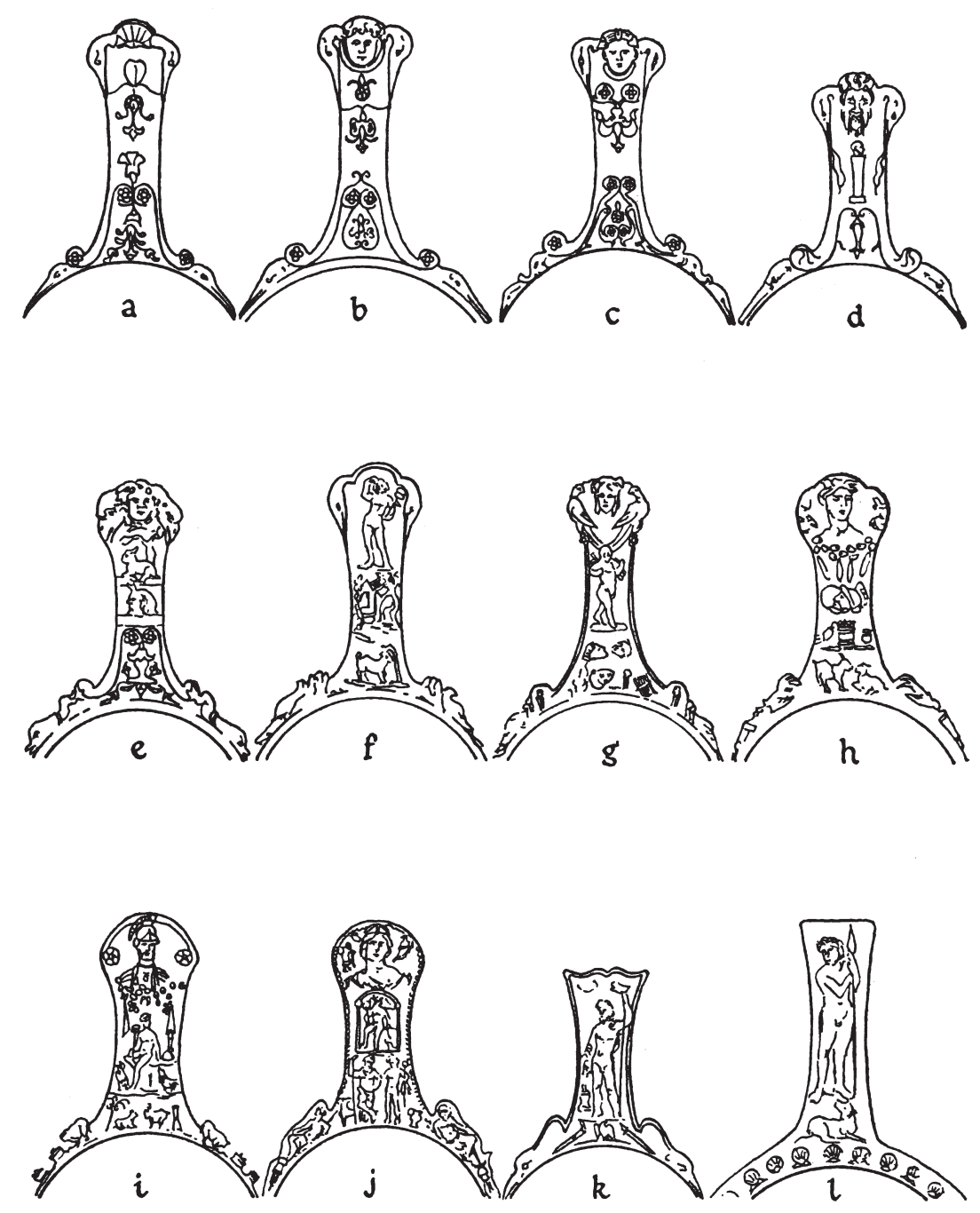

Abb. 13. Silberkasserollen, Typologie nach Strong 1966, Fig. 30 (s. Anm. 37).

Man könnte m. E. derartige Inschriften, wie auch auf unserer Kasserolle vorhanden, sozusagen als Endpunkt der Entwicklung in Richtung der allmählichen Abstraktion und Reduktion des figürlichen Reliefschmucks deuten: Da der flache Stil auch auf unserer Kasserolle bzw. die bereits stark reduzierte Verzierung insgesamt keine figürliche Darstellung (von Götterattributen) mehr zulässt, weiht man das Gefäß „nur noch“ mittels Inschrift. Natürlich fehlt eine entsprechend große, auswertbare Menge an derartig verzierten

Etwa S. KüNZL, Römisches Tafelsilber. Formen und Verwendung, in: Das Haus lacht vor Silber, s. Anm. 16, 21f. - C. FlügEL, Bronze- und Edelmetallverarbeitung, Ausstellungskat. Rosenheim
Kasserollen, um eine solche typologische Reihe zu erstellen. Dennoch dürften die inschriftlich geweihten Silberkasserollen später anzusetzen sein.

Auf der Suche nach konkreten Parallelen finden wir ein geographisch naheliegendes und formal ähnliches Stück im Hortfund aus Manching (Abb. 14; Abb. 15 in noch unrestauriertem Zustand).

Für dessen Vergrabungszeit wird allgemein die 1. Hälfte des 3. Jh. n. Chr. angenommen ${ }^{39}$. Die ovale Griffplatte aus 


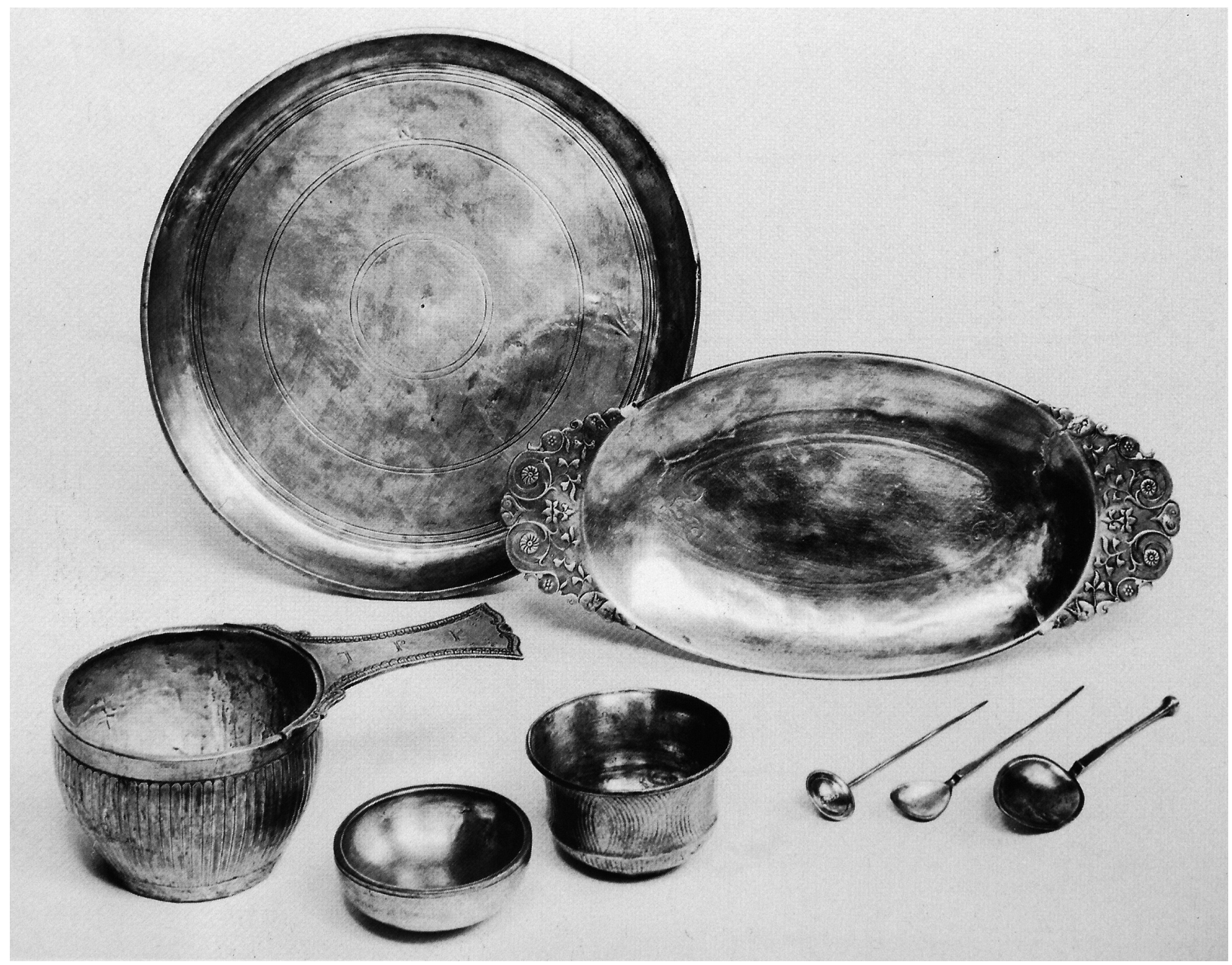

Abb. 14. Manching, Silberhort, nach Künzl 1997, Abb. 13 (s. Anm. 24).

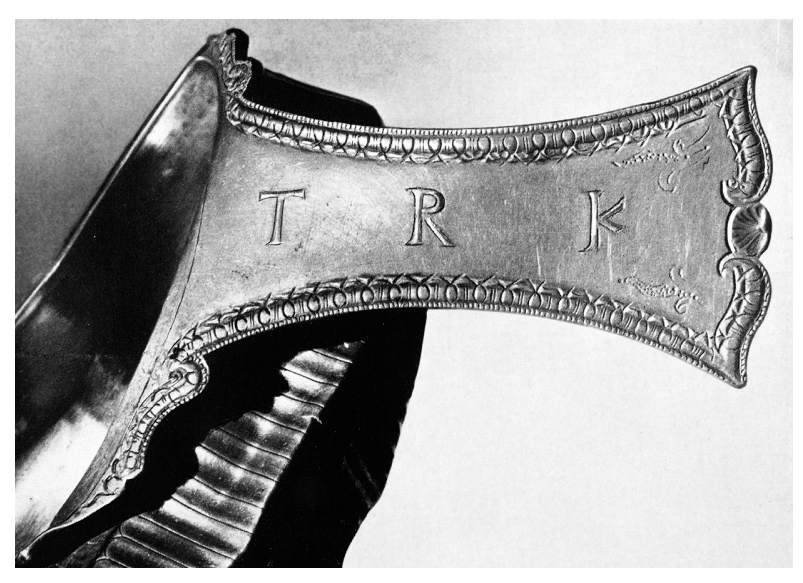

Abb. 15. Manching, Kasserollengriff vor Restaurierung, Krämer 1958, Abb. 24 (s. Anm. 39).

40 Als ein Beispiel von vielen A. W. MeEs, Modelsignierte Dekorationen auf südgallischer Sigillata, Forsch. u. Ber. z. Vor- u. diesem Hort ist als Altstück aus dem frühen 2. Jh. zu betrachten, die Kasserolle selbst ist leider noch immer nicht vorgelegt worden. Bei diesem Stück fällt nicht nur die ähnliche Griffgestaltung auf, sondern auch die Verzierung der Gefäßwand ist mit der Wieselburger Kasserolle vergleichbar. Die Verzierung der Außenwand von Kasserollen ist äußerst selten. Derartige Blattfriese oder Eierstäbe, eventuell gerahmt von Perlenreihen, treten etwa bei der Terra Sigillata bereits im 1. Jh. n. Chr. auf ${ }^{40}$ und sind auch in den folgenden Jahrhunderten zu beobachten.

Anhand dieser langlebigen Standardzier ist die Kasserolle also nicht näher datierbar.

Eine weitere formal ähnliche Silberkasserolle stammt auch aus einem Wieselburg relativ naheliegenden Fundort,

Frühgesch. in Baden-Württemberg 54, 1995, 84f., Taf. 114, Abb. 33. 


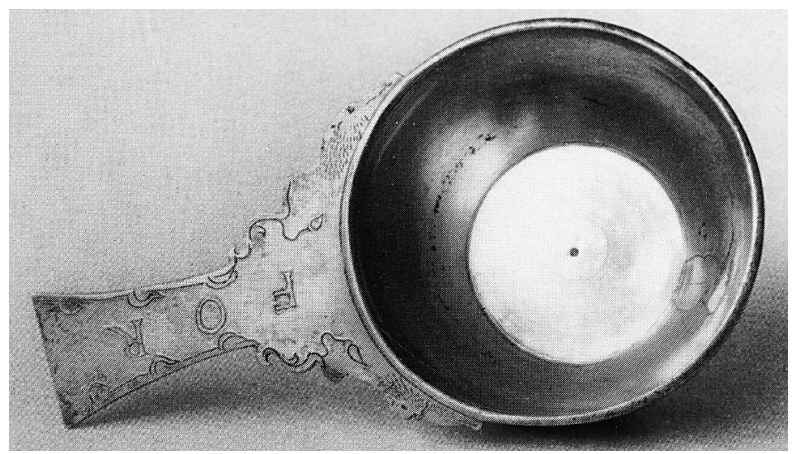

Abb. 16. Enns, Silberkasserolle, nach Dembski 1992, Taf. 15, Abb. 2b (s. Anm. 41).

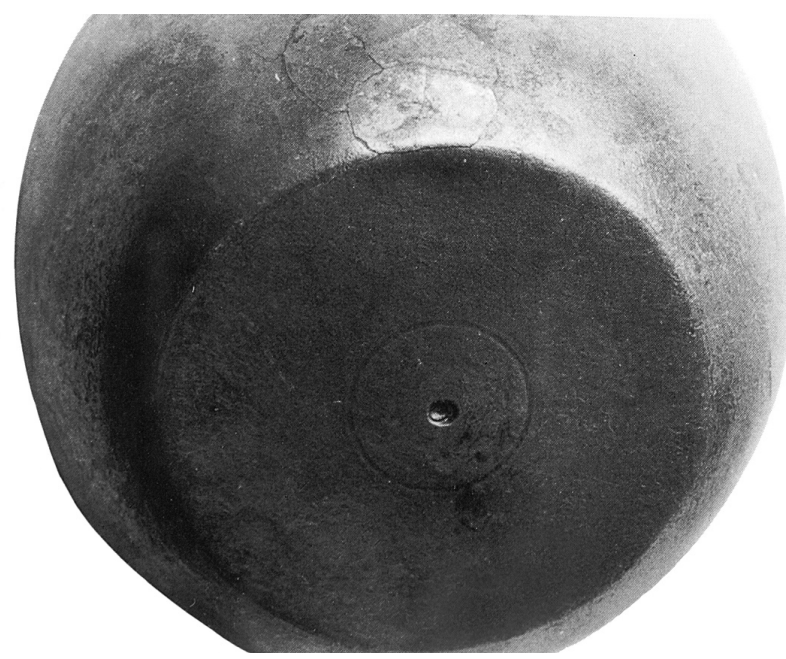

Abb. 17. Enns, Silberkasserolle (Detail), nach Dembski 1992, Taf. 17, Abb. 2f (s. Anm. 41).

nämlich Lauriacum-Enns (Abb. 16, 17) ${ }^{41}$. An der Griffoberseite sind die Buchstaben F O R zu sehen, die das Stück als eine Weihung an Fortuna ausweisen. G. Dembski setzt die Kasserolle, die von Raubgräbern nebst anderen Silberobjekten wohl aus einem Verwahrfund gerissen wurde, an den Beginn des 3. Jh. n. Chr. und zwar aufgrund der Ähnlich-

41 G. Dembski, Das Silbergeschirrdepot aus Lauriacum 1981, in: Festschrift 100 Jahre Museumverein Lauriacum-Enns, 1992, 37 ff., Abb. 2b,f. - G. Dembsky, Tafel- und Wohnluxus, in: H. UbL (Hrsg.), Katalog zur Schausammlung „Römerzeit“ des Museums Lauriacum-Enns, Forsch. in Lauriacum 12, 2, 1997, 331 ff.

42 Dazu sei aber einschränkend bemerkt, dass die Datierung der Manchinger Kasserolle keineswegs gesichert ist. Als Vergrabungszeit des Depots, in dem auch Altstücke vorkommen, wird die 1. Hälfte des 3. Jhs. angenommen.

43 Im Museum Bad Deutsch-Altenburg, Inv. Nr. 11670

44 Kunsthist. Mus. Wien, Inv. Nr. VII A 17

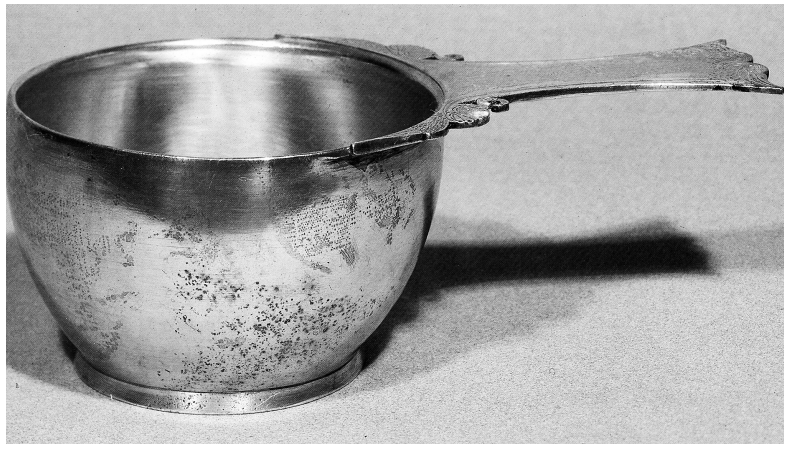

Abb. 18. Mailand, Silberkasserolle, nach Pirzio 1991, Abb. 198 (s. Anm. 45).

keiten zur Kasserolle aus Manching ${ }^{42}$. Eine weitere Silberkasserolle, die auf heute österreichischem Boden zutage gekommen ist, stammt aus Carnuntum ${ }^{43}$ mit der Weihung D I A N(E). Im Kunsthistorischen Museum Wien befindet sich ein Stück mit einer Weihung M E R C, also an Merkur $^{44}$.

Ein formal sehr ähnliches Gefäß befindet sich in Mailand $^{45}$ (Abb. 18). Hier weist der Griff vier Vogelköpfe auf. Diese erscheinen auch - im Gegensatz zu älteren Kasserollen - nicht mehr als stark plastisch gearbeitetes Relief, sondern bestehen aus feinen Rillen und kleinen, gepunzten Vertiefungen. Das Stück wird von L. Pirzio ins 3. Jh. n. Chr. datiert.

Eine große Anzahl an Silberkasserollen stammt aus dem gallischen Bereich. F. Baratte legte sie monographisch vor ${ }^{46}$. Hier wird die große Formenvielfalt erkennbar, man kann aber eine gewisse Grundtendenz ablesen: Die Griffoberseiten der Silberkasserollen des 1. Jh. zeigen sehr plastisch ausgeführte Vogelkopfreliefs. Sie werden später nur durch feine Rillen oder Punzen angegeben, das Relief verflacht. Die Darstellungen werden insgesamt auch abstrakter und statischer ${ }^{47}$. Am Ende dieser Entwicklung erscheinen sie nur noch in ihren Umrissen, wie etwa am Griffansatz unserer Kasserolle. F. Baratte verweist hierbei zwar auf die Schwie-

45 L. Pirzio, L'argento dei Romani, vasellame da tavola e d'apparato, Rom 1991, Abb. 198.

46 Baratte, s. Anm. 21.

47 Baratte, s. Anm. 21, Abb. 153. Die hier abgebildete Kasserolle wird ins 2.-3. Jh. datiert. In Abb. 73 zeigt F. Baratte den Griff einer Platte aus dem Hildesheimer Schatz des 1. Jh.. Dort sehen wir noch stark plastisch ausgeführte Vögel, die munter im bewegten Wasser schwimmen. Diese plakative Gegenüberstellung soll beispielhaft die fortschreitende Verflachung der Reliefzier demonstrieren. 


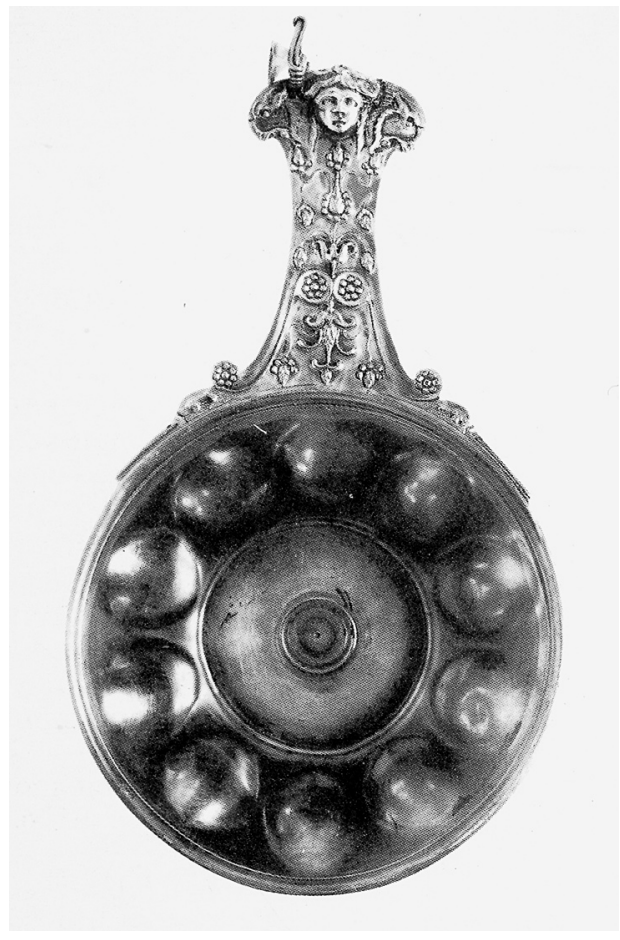

Abb. 19. Tekija, Silberkasserolle, nach Popovic 1994, Nr. 164 (s. Anm. 49).

rigkeiten der näheren Datierung, setzt aber die Kasserollen, bei denen die Verzierung bereits sehr abstrakt ist, ins 3. Jh. n. Chr.. Wichtig ist, dass stilisierte Vogelköpfe als Randzier noch lange fortleben ${ }^{48}$.

Obwohl die Funddichte in Italien oder Gallien ungleich größer, der Publikationsstand ungleich besser ist, scheint der Balkanraum einen genaueren Blick wert zu sein: Im Silberhort von Tekija befinden sich neben Schmuck und Löffel auch Silbergefäße ${ }^{49}$. Die Kasserolle italischer Herkunft, stark plastisch verziert, datiert in die 2. Hälfte des 1. Jhs. n. Chr. (Abb. 19). Als Schlussmünze gilt eine Prägung Domitians aus dem Jahr 81.

Wichtig sind nun zwei weitere Horte, aus denen rein formenkundlich-typologisch betrachtet die nächsten Verwandten zur Kasserolle aus Wieselburg stammen: Einerseits der Hort von Bela Reka und eine Kasserolle aus Gornji Branetici $^{50}$. Im Hort von Bela Reka, der auch viele Altstücke

48 M. Martin, Weinsiebchen und Toilettgerät, in: Cahn, KaufmannHeinimann, s. Anm. 7, 105ff., Taf. 31.3; M. Martin legt u. a. ein Weinsiebchen aus Bifrons aus dem 6. Jh. n. Chr. vor, noch immer ist das Vogelkopfmotiv fester Bestandteil der Griffgestaltung.

49 I. Popovic, Antique Silver from Serbia, Belgrade 1994, 91 ff.

50 I. Popovic (Hrsg.), Silver Workshops and Mints, National Museum Belgrade, Monogr. 9 ,1995, 160 ff., Fig. 12, Fig. 21-24.
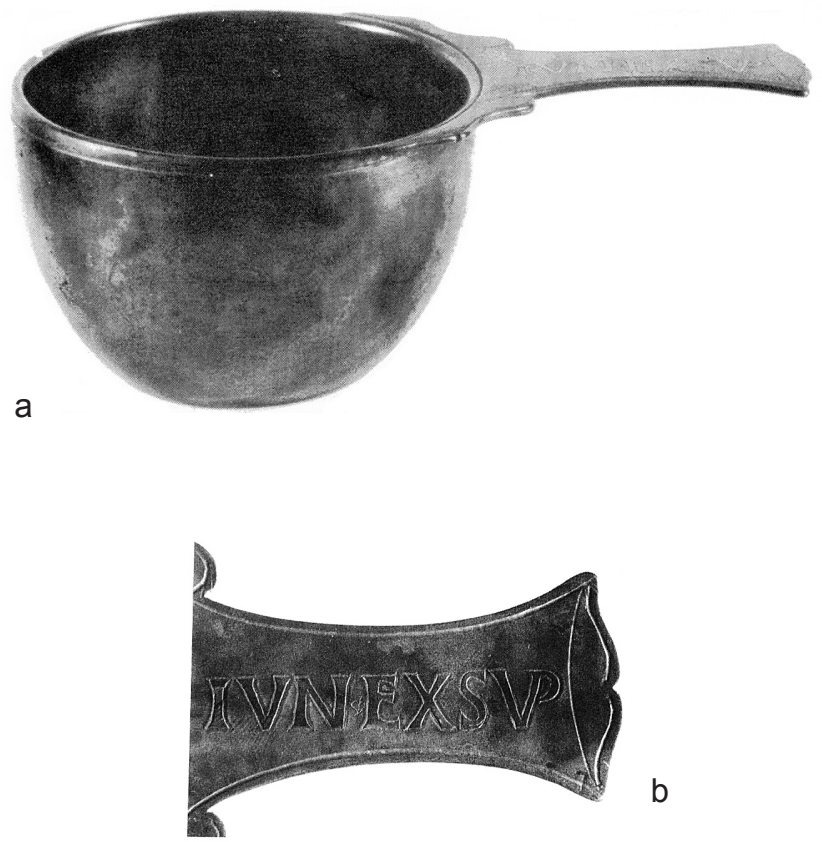

Abb. 20. Bela Reka, Silberkasserolle, nach Popovic 1995, Fig. 22/23 (s. Anm. 50).

(Schmuck aus Silber und Gold) enthält, befindet sich ein sehr gutes Vergleichsstück (Abb. 20). An der Bodenunterseite der Kasserolle liest man die Inschrift: Fl. Marcel(1?)us, wohl der Besitzer.

Die Inschrift IVN EXSVP (Iunona Exsuperantissima) sei von großer Bedeutung für die Datierung: Das Attribut exsuper/exsuperatus finde man oft im Zusammenhang mit Jupiter, selten wie hier mit Bezug auf Juno. Wichtig sei, dass Commodus diesen Beinamen offiziell übernahm (etwa in der Münzprägung) und dieser während seiner Regierungszeit außergewöhnlich oft als Attribut des Jupiter auftaucht. I. Popovic hält folglich die Fertigung der Kasserolle in den beiden letzten Jahrzehnten des 2. Jhs. für sehr wahrscheinlich, insbesondere aufgrund der vergesellschafteten Schlussmünze, eine Prägung des Commodus aus dem Jahre 182 n. Chr.. Demzufolge läge hier eine der bestdatierten Silberkasserollen vor $^{51}$.

51 I. Popovic, The Bela Reka Hoard, National Museum Belgrade, Monogr. 7, 1994, 57. Man muss aber der Vollständigkeit halber ergänzen, dass die Schlussmünze nur einen terminus post quem für den Vergrabungszeitpunkt des Hortes liefert und keine exakte Datierung der Kasserolle zulässt. 


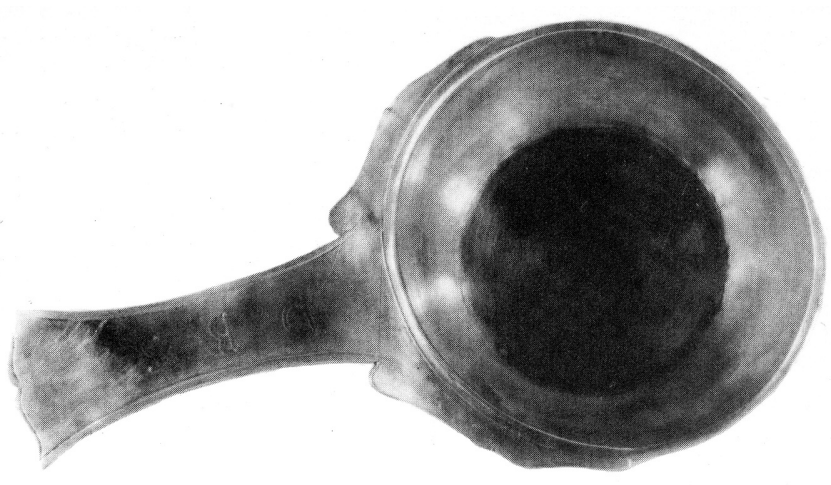

Abb. 21. Gornji Branetici, Silberkasserolle, nach Popovic 1995, Fig. 21 (s. Anm. 50).

Am Griff der Kasserolle aus Gornji Branetici (Abb. 21), von I. Popovic ans Ende des 2. bzw. den Anfang des 3. Jhs. gesetzt, sehen wir die Inschrift D B S (Deo Baccho Sacrum?). Die besprochenen Kasserollen aus Bela Reka und Gornji Branetici zeigen an den Griffen, die je in Form von Fischschwänzen enden, abstrahierte, nur noch in den Konturen erkennbare Vogelköpfe.

Eine andere Kasserolle aus dem Nationalmuseum Belgrad (Fundort unbekannt) ist mit stark stilisierten, aber noch erkennbaren Vogelköpfen verziert (Abb. 22). I. Popovic datiert sie in die erste Hälfte des 2. Jhs. und nimmt folgende chronologische Entwicklung für die besprochenen Stücke aus dem Balkanraum an ${ }^{52}$ : Während bei älteren Kasserollen das Vogelkopfmotiv deutlich ausgearbeitet ist, wird es demnach in der ersten Hälfte des 2. Jhs. (Kasserolle unbekannter Herkunft) immer abstrakter dargestellt, bis es in der zweiten Hälfte des 2. Jhs. / Anfang des. 3. Jhs. gänzlich verschwindet und nur noch in der Grundform des Griffes erkennbar ist (Kasserollen aus Bela Reka und Gornji Branetici).

Es erhebt sich aber die aber Frage, ob die „Degeneration“ des Vogelkopfmotives ein zwingend chronologisches Merkmal sein muss. I. Popovic hält die Kasserollen aus Bela Reka oder Gornji Branetici für lokale Produkte.Vielleicht

52 I. Popovic, s. Anm. 51, 56. „This simplification of the original ornament illustrates the chronological differences between the mentioned specimens... the patera from the unknown archaeological site..., can be attributed to the first half of the II. century, the patera of Bela Reka and Rudnik... to the II.-III. century..."

53 Popovic, s. Anm. 51, 56. Wie wir auch von anderen Denkmälergattungen, etwa der Plastik wissen, ist der flache (Verzierungs-)Stil der Spätantike keinesfalls als Degeneration zu verstehen. Entsprechende Techniken, besonders die des spätantiken Kunstschaffens (z.B. Bohrer statt Meissel beim (Kaiser-)Portrait), sind oft sogar

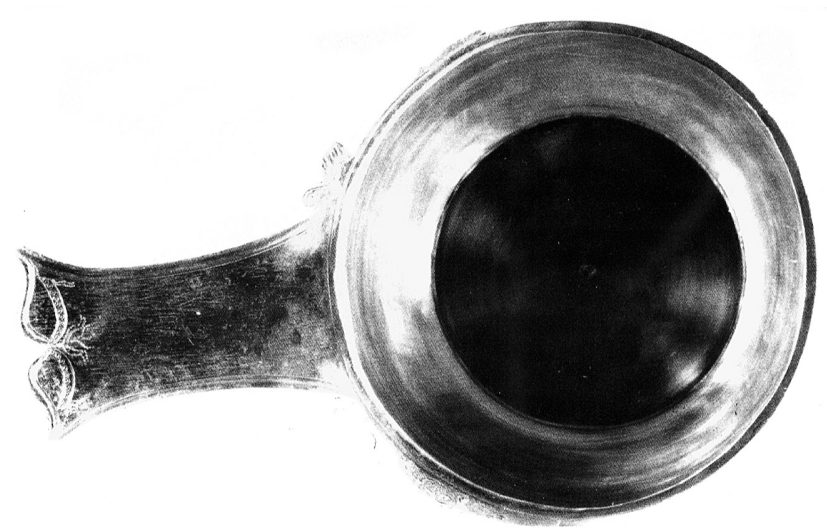

Abb. 22. Fundort unbekannt, Silberkasserolle, nach Popovic 1995, Fig. 25 (s. Anm. 50).

ist der ,vereinfachte“, oder besser ,,andere“ Stil auch so zu erklären: Im Gegensatz zu den reich reliefverzierten gallischen Produkten fertigte man hier möglicherweise (zeitgleich?) etwas weniger üppig verzierte Gefäße. Weiters könnte der von I. Popovic zweifelsohne richtig gemeinte englische Begriff „degeneration“ leicht missverstanden werden. Man könnte ihn irrtümlich mit der natürlich längst überholten Vorstellung der Degeneration der (z.B. spätantiken) Kunst in Verbindung bringen ${ }^{53}$. Trotz dieser Überlegungen möchte ich mich dem Datierungsansatz von I. Popovic anschließen. Somit befindet sich das Wieselburger Stück stilistisch betrachtet zwischen der Kasserolle unbekannten Fundortes (1. Hälfte 2. Jh.) und denen aus Bela Reka und Gornji Branetici, die nach I. Popovic zwischen 182 n. Chr. und Anfang 3. Jh. zu datieren sind.

Bei der Kasserolle aus Wieselburg sind die Vogelköpfe am Griffende noch vorhanden. Somit könnte man das Gefäß nun grob in die 2. Hälfte des 2. Jh. n. Chr. datieren. Eine engere zeitliche Eingrenzung scheint beim aktuellen Stand der Forschung nicht möglich.

Der Blick auf den Balkan bietet nicht nur hinsichtlich der Datierung unserer Kasserolle, sondern auch bezüglich der Herkunft interessante Aspekte. Hier befinden sich reiche arbeitsintensiver als die der frühen Kaiserzeit. Die Eleganz etwa des augusteischen Klassizismus (Portrait, historische Reliefs o. ä.) „blendet“ bekanntlich. Natürlich begegnet dieses Phänomen auch im Metallhandwerk: Die starke Plastizität, die „,barocke“ Verzierung von frühen Objekten, wie wir sie etwa im Schatz von Hildesheim antreffen, wirkt heute auf den ersten Blick reicher, „künstlerisch anspruchsvoller“ als etwa sehr mühsam gefertigte, flache Niello-Einlegearbeiten der Spätantike (z.B. Kaiseraugst). Insoferne könnte der von Popovic gewählte Begriff ,,degeneration" leicht missverstanden werden. 
Silbervorkommen, die Provinz Moesia betrachtete man in Rom als „Land des Silbers“ ${ }^{54}$.

I. Popovic führt Belege für Silberverarbeitung für verschiedene Regionen des Balkans an. Wichtige Hinweise finden sich etwa in der Gegend um Rudnik. Auch indirekte, aber sehr stichhaltige Belege wie die große Zahl an Silberbarrenfunden auf dem Balkan lassen auf eine intensive Silberindustrie schließen. Diese Barren, von staatlichen Betrieben gegossen, tragen auch Inschriften, die den Namen des Herstellers, Ort und Gewicht angeben. Sie sind oft wie Münzen mit dem Kaiserbild gestempelt, also gut datierbar. Bereits ab dem 1. Jh. n. Chr. existierte demzufolge diese Industrie in den Balkanprovinzen. Und zwar sowohl Abbau und Verarbeitung von Silber als auch die Fertigung von Endprodukten. Sirmium und Naissus waren staatliche Münzstätten, insbesondere für das 4. Jh. liegen Inschriften vor, die beide Städte auch als Produktionsorte von Silberobjekten mit offiziellem Charakter ausweisen ${ }^{55}$. Diese Industrie fand ihr Ende offenbar erst gegen Ende des 4. Jhs. bzw. im Laufe des 5. Jhs. nach der spätantiken Hochblüte.

Der verhältnismäßig gute Publikationsstand aber auch die hohe Funddichte an Silberobjekten im heutigen Frankreich haben m. E. dazu geführt, die Silberproduktion Galliens etwas überzubewerten. Die römische Silberindustrie auf dem Balkan ist in ihrer Bedeutung keineswegs zu unterschätzen.

Ich nehme sogar an, dass auch die Kasserolle aus Wieselburg, wie die aus Bela Reka oder Gornji Branetici, lokale Produkte aus dem Balkanraum sind. In gallischen Inventaren konnten keine nur annähernd gute Entsprechungen ausgemacht werden. Unser Fundstück liegt auch geographisch betrachtet näher an dieser östlichen Silbergeschirrindustrie als etwa an Gallien. Um dies zu konkret belegen zu können, sind Analysen und großräumige Kartierungen bezüglich Metallzusammensetzung und Herstellungstechnik unumgänglich.

\section{Inschriften auf der Kasserolle}

\section{Weihinschrift - Jupiterkult}

Auf der Griffoberseite befinden sich die Lettern $\mathrm{I}+\mathrm{O}+\mathrm{M}$, die von der Schale zum Griffende hin zu lesen sind (Abb.

54 Popovic, s. Anm. 49, 77 ff.

55 I. Popovics, Les productions officielles et privées des ateliers d'orfevrerie de Naissus et de Sirmium, Antiquité Tardive 5, 1997, $133 \mathrm{ff}$.

56 Etwa H.-P. Kuhnen, Religio Romana. Wege zu den Göttern im alten Trier, Schr. d. Rhein. Landesmus. 12, 1996, 96 ff.
2, 4 und 9). Das Gefäß ist somit Iovi Optimo Maximo, Jupiter geweiht. Die Kasserolle wurde also wohl für einen sakralen Zweck angefertigt. Zu Jupiter sei hier nur kurz festgehalten, dass er als oberster Gott der Staatsreligion galt, der bis in die Spätantike oberster Schwurgott blieb ${ }^{56}$. Man opferte ihm Schwein, Schaf und Stier (Suovetaurilien). Der Kaiser erkoren Jupiter zu ihrem persönlichen Schutzgott, oder stellte sich auch als seine direkten Stellvertreter dar. In Noricum sind die meisten inschriftlichen Götterdedikationen Jupiter gewidmet ${ }^{57}$. P. Scherrer konnte weiters zeigen, dass $63 \%$ der 111 von ihm behandelten norischen Jupiterdedikationen von Beamten vorgenommen wurden. Diesen Umstand führt er darauf zurück, dass sie bei ihrem Amtsantritt üblicherweise vota ablegten. Aber auch Militärs und Privatpersonen opferten dem obersten römischen Gott. Die Verbreitung dieser Weihungen konzentriert sich auch in Noricum auf städtische Bereiche. Jupitertempel, für Noricum mancherorts von der älteren Forschung postuliert, sind archäologisch kaum fassbar. Hierfür liegen hauptsächlich indirekte Belege vor, etwa die Überlieferung einer aedes für den obersten Schutzgott im Chiemseegebiet.

Betrachten wir nun mögliche Jupiterheiligtümer, die in der Umgebung der Fundstelle bei Wieselburg liegen. In diesem Zusammenhang könnten drei Altarsteine von Interesse sein, die bei Sondagen im Bereich der Kirche von Sarling an der Donau entdeckt wurden ${ }^{58}$. Man hat sie mit der Kapitolinischen Trias in Verbindung gebracht. Sie weisen allerdings keinerlei Inschrift auf. Die Bausubstanz, die teils als Aufgehendes im leider verputzen Mauerwerk der Kirche zu erahnen und teils ergraben ist, wurde auch als Tempel gedeutet. Die damalige Forschung deutete ja nur allzu oft ältere Bausubstanz in heutigen Kirchen als Reste römischer Tempel. Wenn schon römisch, möchte ich hier eher die Reste eines Limes-Wachturms erkennen. Dafür spricht auch die topographische Situation, es bietet sich ein hervorragender Blick über die Donau. Eine kleine Sondage wäre sehr aufschlussreich. Ein gut erhaltener Altar, der Jupiter Optimus Maximus geweiht ist, stammt aus Pöchlarn an der Donau, also bereits in einiger Entfernung. Beide Fundorte, Sarling und Pöchlarn, sind aber eher im (für Jupiterdedikationen „anfälligen“) Zusammenhang mit römischen Militärlagern bzw. dazugehörigen Siedlungen zu sehen, während unser

57 P. SCHERRER, Gottheiten im römerzeitlichen Noricum, Diss. Univ. Wien, 1984, $25 \mathrm{ff}$.

58 Denk, s. Anm. 2, 73 f., Abb. 29 
Stück in einer Gegend etwas abseits der Donau gefunden wurde.

Weder für Sarling, Pöchlarn noch Wieselburg selbst lassen sich Jupiterheiligtümer lokalisieren, bestenfalls nur indirekt archäologisch belegen. In diesem Zusammenhang sei nur der Vollständigkeit halber der Dolichenusfund von Mauer an der Url erwähnt, das nur etwa $35 \mathrm{~km}$ Luftlinie von Wieselburg entfernt liegt ${ }^{59}$.

Die unklaren Fundumstände unserer Kasserolle erlauben keine direkten Bezüge zu einem Jupiterheiligtum (Inventar) in der Nähe der Fundstelle. Das Stück könnte verschleppt und somit auch fernab jeglicher Kultanlage vergraben worden sein. Th. Fischer betont jüngst für den norischen Bereich ${ }^{60}:$,...eine Vielzahl von Heiligtümern lässt sich überhaupt nur als verlagerte und einzeln gefundene Weiheinschriften und Kultbilder fassen."

Er wertet die Kasserolle aus Wieselburg als Beleg furr ein ,unbekanntes, ländliches Jupiterheiligtum“. Dem möchte ich voll zustimmen, die Lokalisierung eines solchen bleibt aber völlig offen.

\section{Gewichtsangabe}

Auf der Griffunterseite ist, dicht am Rand der Schale, also recht unauffällig, eine aus feinen Punzen bestehende, zweite Inschrift angebracht; eine Gewichtsangabe der Kasserolle (Abb. 3, 5 und 10) ${ }^{61}$ :

Die Deutung ist nicht ganz unkompliziert. Das erste Zeichen ist als Einleitung der Gewichtsangabe zu verstehen (Ligatur PL):

„L“ " steht für 1 Pfund - 327,45 g; ,S“ (semis) = 1/2 Pfund $-163,725 \mathrm{~g}$;

,::.“ (quincunx $)=5$ Unzen (1 Unze $=1 / 12$ Pfund) $136,4375 \mathrm{~g}$; das folgende Zeichen eine semuncia, also $1 / 2$ Unze $-13,64375 \mathrm{~g}$; es folgen vier sextulae $=2 / 3$ Unze (1 sextula $=1 / 6$ Unze $)-18,19167 \mathrm{~g}$.

Dies ergibt ein Gesamtgewicht von 659,45 g. Das tatsächliche beträgt $614 \mathrm{~g}$.

E. Weber schlägt aber auch eine weitere Möglichkeit der Leseweise vor:

Die vier senkrechten Striche am Ende der Inschrift, deren erster - wie auch sonst üblich - nach oben verlängert ist, könnte man nicht als sextulae sondern als scripula auffassen.

59 R. Noll, Das Inventar des Dolichenusheiligtums von Mauer an der Url, Der röm. Limes in Österr. 30, 1980, 25 ff.

60 Th.Fischer, Noricum, Zaberns Bildbände zur Archäologie, Sonderbände der antiken Welt, Mainz 2002, 123 ff.

61 R. IgL, E. WeBer, Ein archäologisch-epigraphischer Kommentar
1 scripulum $=1 / 24$ Unze, die vier Striche würden demnach 1/6 Unze oder 4,55 g ergeben.

Demzufolge würde sich das Gesamtgewicht auf etwa 645,80 g reduzieren, die Differenz zum Sollgewicht macht dann nur noch etwa $32 \mathrm{~g}$ aus.

Wie kommt es aber zu solchen Abweichungen?

Einerseits bewirkt die ständige Oxidation flächigen Material- also Gewichtsverlust. Andererseits liegt ein Riss vor, am Griffende ist ebenfalls etwas Metall (vom Pflug) abgeschabt.

M. Martin versucht, die Abweichungen von realem Gewicht zu den inschriftlichen Angaben für die Augster Silberobjekte auch folgendermaßen zu erklären ${ }^{62}$ : Die angegebenen Gewichte beziehen sich möglicherweise auf die unbearbeiteten, also rohen Objekte, die durch die Technik des Metallschneidens und -drehens einen doch nicht unbeträchtlichen Materialverlust erfuhren und somit an Gewicht verloren. Gewichtsschwund seit der Antike ist also aus mehreren Gründen nachvollziehbar. Offen bleibt aber die Frage, weshalb das Gewicht bei unserer Kasserolle so umständlich angegeben wurde. Möglicherweise bildet sie die Reihenfolge der Gewichte ab, wie man sie auf die Waage legte. Eine andere Möglichkeit wäre auch eine dritte Lesung. Sie stellt hier nur einen Vorschlag dar, der zugegebenermaßen gewagt ist. M. Martin behandelt u. a. auch die neun Gewichtsangaben, die sich auf drei Barren und vier Gefäßen aus dem Augster Schatz befinden ${ }^{63}$. Unter den „fraglichen“ Gewichtsangaben führt M. Martin S-förmige Zeichen an, die an ihren oberen Enden kleine Schrägstriche oder Haken aufweisen. Er meint, dass es sich hierbei um eine Abwandlung des Zeichens S (semis), also $1 / 2$ handeln könnte. Wollte man den Bruch $3 / 4$ darstellen, so wurde dem Zeichen für $1 / 2$ ein kurzer Strich angehängt. Die Objekte, auf denen diese Zeichen zu sehen sind, wiegen einerseits $21,89 \mathrm{~g}$, das zweite wohl etwas mehr (es ist fragmentiert), was etwa dem Gewicht einer dreiviertel Unze $(20,46 \mathrm{~g})$ entspricht. Auch auf unserer Kasserolle befindet sich ein derartiges „S“, das oben einen kleinen Strich aufweist (Abb. 5). Zum Pfund gehörig, könnte man nun lesen:

1 Pfund $+3 / 4$ Pfund +2 Unzen, wiedergegeben durch die beiden dem ,'S“ nachfolgenden Marken.

Den darauffolgenden, einzelnen Punkt müsste man als bloßes Satzzeichen, als Leermarke zwischen der Angabe in ganzen Unzen und ihrer kleineren Untereinheiten interpre-

zu einer Inschrift aus Kärnten, in: Carinthia Romana und die römische Welt, Festschr. Piccotini, Klagenfurt 2001, 263 ff.

62 M. Martin, Stempel, Gewichtsangaben und Inschriften, in: CAHN, Kaufmann-Heinimann, s. Anm. 7, 382.

63 Martin, s. Anm. 62, Abb. 150. 
tieren (wie etwa die Dreiecke zwischen den Buchstaben der Jupiterweihung I O M ). Die folgenden Zeichen sind: semiuncia $(13,64375 \mathrm{~g})$ und scripula $(4,55 \mathrm{~g})$. Dies ergibt ein Gewicht von $645,80 \mathrm{~g}$ und entspricht interessanterweise exakt dem der zweiten Leseweise von E. Weber. Er hält diesen dritten Vorschlag zur Entschlüsselung der Inschrift für „weniger wahrscheinlich, aber nicht auszuschließen“"64.

Wie dem auch sei, die Gewichtsangabe sicherte dem Auftraggeber, dass die abgegebene Menge Silber auch tatsächlich verarbeitet wurde. Durch die Angabe dokumentiert der Stifter vor allem wohl den Wert des Opfers an Jupiter. Der Macherlohn für das Kunstobjekt, der auch wesentlich über dem Materialwert gelegen sein mag, interessiert in diesem sakralen Zusammenhang offenkundig nicht.

\section{Funktionsfragen}

Die Funktion von römischen Gefäßen bestimmen zu wollen, ist eine schwierige Aufgabe.

In den antiken Schriftquellen wird die Verwendung im Alltag kaum erwähnt. Es gelingt nicht immer, überlieferte Bezeichnungen mit vorhandenen römischen Gefäßformen zu identifizieren. Bei der Zweckbestimmung entstehen die größten Fehler dadurch, dass man von modernen Gegebenheiten ausgehen möchte. In der Antike wurden Gefäße wohl multifunktionaler, aber auch anders verwendet als vergleichbare Formen heute. Ein weiteres Problem ist, dass innerhalb des Reiches ja auch regional unterschiedliche Tischsitten, Ess- und Trinkgewohnheiten anzunehmen sind. W. Hilgers unterscheidet zwischen den in unserem Zusammenhang wichtigen Küchengefäßen (vasa conquina(to)ria) und Tischgefäßen (vasa escaria und vasa po(ta)toria) ${ }^{65}$. Bei den Tischgefäßen sei grundsätzlich zwischen Essgefäßen (Servier-, Ess-, und Beigefäße) und Trinkgefäßen (Becher, Krüge für Wein und Wasser und weitere Zubereitungsgefäße) zu unterscheiden. Geschirr zum Auftragen der Speisen wurde ministeria genannt. Die Namen der variantenreichen Becher bzw. Trinkgefäße sind vielfältig. Neben Krugformen und Mischgefäßen sind für Schöpfgefäße die Bezeichnungen cyathus, simpulum, simpuvium überliefert.

64 Nach freundl. Mitteilung von E. Weber, Inst. f. Alte Geschichte, Univ. Wien.

65 W. Hilgers, Lateinische Gefäßnamen, Bonner Jahrb., Beih. 31, 1969, 68ff; 225 ff.

66 Hilgers, s. Anm. 65, 242ff. Hilgers bringt u. a. folgende Beispiele der Verwendung: als Opfergefäß: Vergil, Aen.7, 133: nunc pateras libate Iovi..; beim Weinopfer: Ovid, Met. 15,574: ...vinaque dat pateris...; als Sakralgefäß allgemein: Ovid, Met. 13, 702: ...sacerdoti dant pateram.
W. Hilgers sondert dann als weitere Gruppe die Sakralgefäße ab: Er betont dabei, dass sie gleichzeitig auch alläglichen Zwecken dienen konnten, weshalb kaum eigene Namen überliefert sind. Die Kultgefäße dienten dabei als Opfergeräte, aus denen die flüssigen oder festen Gaben gespendet wurden. Die patera etwa beim Wein- und Blutopfer. So wird aus der patera dem Opfertier die Flüssigkeit zwischen die Hörner geschüttet; die Opfernden trinken auch aus der patera; sie wird öfters als Weihgeschenk genannt, seltener als Räuchergefäß. Als verwendetes Material wird ausschließlich Edelmetall, Gold oder Silber erwähnt ${ }^{66}$. Aus der schriftlichen Überlieferung, die sie hauptsächlich als Kultgerät präsentiert, ergibt sich für die patera folgende Erscheinung: Sie ist niedrig und weit offen, entspricht also nicht der Form der relativ tiefen Schalen von Kasserollen. W. Hilgers: „Man pflegt heute... Kellen oder Kasserollen als patera zu bezeichnen. In Wahrheit ist uns aber ihre Benennung in der Antike unbekannt..." Sie werden in der Literatur dennoch immer wieder fälschlicherweise als paterae bezeichnet ${ }^{67}$. Insgesamt werden oft uneinheitliche Begriffe für unterschiedliche Gefäßformen verwendet. Besonders problematisch ist die Abgrenzung der grundsätzlich relativ ähnlichen Grundformen von Griffschale, Kelle und Kasserolle. Griffschalen unterscheiden sich von den Kasserollen dadurch, dass die Griffschalen sehr flach sind und hohle, hülsenartig-zylindrische Griffe, oft mit Tierprotomen (z.B. Widder- oder Löwenkopf) aufweisen. Ein schönes Stück stammt aus Zell am See (Abb. 23).

Sie unterscheiden sich aber auch in ihrer Funktion. Die Griffschale gehört, wie H.-U. Nuber anhand von Grabfunden, Verzierungstechniken und bildlichen Darstellungen nachweisen konnte, immer zusammen mit einer Kanne zu einer festen Gefäßgarnitur ${ }^{68}$. Kanne und Griffschale als Grabbeigabe galten in der Forschung meist als Kultgeräte, mit denen man Wein opferte ${ }^{69}$. H.-U. Nuber hingegen konnte zeigen, dass dieses Gefäßpaar dem Händewaschen gedient hat. Er betont, dass die Beigabe von Opfergerätschaften in römischen Gräbern unüblicher gewesen sei als etwa Speise- und Trankbeigabe. Griffschale und Kanne seien als Waschgarnitur, als Zeichen gehobener Tischsitten zu

$67 \mathrm{Um}$ ein Zitat von vielen herauszugreifen: Etwa I. Popovic verwendet den ungesicherten lateinischen Begriff (s. Anm. 50, etwa Fig. 21 und auch Anm. 52). Auch in anderen namhaften Publikationen wird immer wieder der Begriff patera auf Kasserollen bezogen.

68 H.-U. Nuber, Kanne und Griffschale. Ihr Gebrauch im täglichen Leben und die Beigabe in Gräbern der römischen Kaiserzeit, Ber. Röm.-Germ. Komm. 53, 1972, 1 ff.

69 Nuber, s. Anm. 68, 177 ff. 
verstehen und in diesem Kontext auch mit ins Grab gegeben worden. Bildliche Darstellungen zeigen dieses meist von Dienern getragene Gefäßpaar in entsprechender Funktion. H.-U. Nuber hält trulleum für die antike Bezeichnung der Griffschale ${ }^{70}$. Wie dem auch sei, man sollte an H. U. Nubers klar definierten, unmissverständlichen Terminus Griffschale festhalten. Wichtig ist, diesen Begriff nur auf ebendiese spezielle Form mit zylindrischem Griff und sehr flacher Schale anzuwenden ${ }^{71}$.

Sowohl Kelle/Sieb-Garnituren als auch Kasserollen wurden und werden immer wieder unterschiedlich angesprochen. Kelle und Sieb treten oft vergesellschaftet auf und sind so dimensioniert, dass die Siebe genau in die Kellen passen. Ihre Böden sind meist leicht gerundet. Kasserollen weisen meist völlig flache Böden auf. Außerdem sind die Griffe bei Kelle/Sieb-Garnituren länger und meist ruderförmig. Sie sind auch insgesamt leichter, dünnwandiger ausgeführt und seltener verziert als Kasserollen.

Die Griffe sind sowohl bei Kellen als auch bei Kasserollen flach und somit klar von den oben besprochenen Griffschalen abzugrenzen.

Diese drei Typen ähnlicher Grundform wurden wohl nicht zuletzt wegen der uneinheitlichen Terminologie oft verwechselt. Irreführend ist auch die Verwendung der vermeintlich objektiven, tatsächlich aber kaum gesicherten lateinischen Namen dieser unterschiedlichen Gefäße.

Die Problematik der uneinheitlichen Terminologie soll an einem Beispiel dargelegt werden:

A. Radnoti sondert in seiner damals bahnbrechenden Arbeit den Typ „Griffige Opferschalen (Pateren)“ $a b^{72}$. Wie H.-U. Nuber aber zeigen konnte, dienten sie dem Händewaschen bei Tisch, also nicht der Opferhandlung ${ }^{73}$. Der Terminus patera, den A. Radnoti beifügt, war nicht der antike Name für solche Gefäße (was H.-U. Nuber und W. Hilgers ja eindeutig zeigten). A. Radnotis auf den ersten Blick sehr ähnliche Benennung impliziert also gleich zwei „Fehler“.

Es ist offenkundig problematisch, rekonstruierte Funktion/en eines Gefäßes in moderne Begriffe einfließen zu lassen. Um dies zu vermeiden, könnte man sie etwas umständlicher charakterisieren:

71 Etwa bei Z. Karasova, Die römischen Bronzegefäße in Böhmen, Fontes Arch. Prag. 22, 1998, 38 ff. werden diese Griffschalen dann wieder als Kasserollen mit festem horizontalen Griff bezeichnet. Wenn auch vielleicht auf Übersetzungsschwierigkeiten zurückzuführen, kann diese uneinheitliche Terminologie für gehörig Ver-

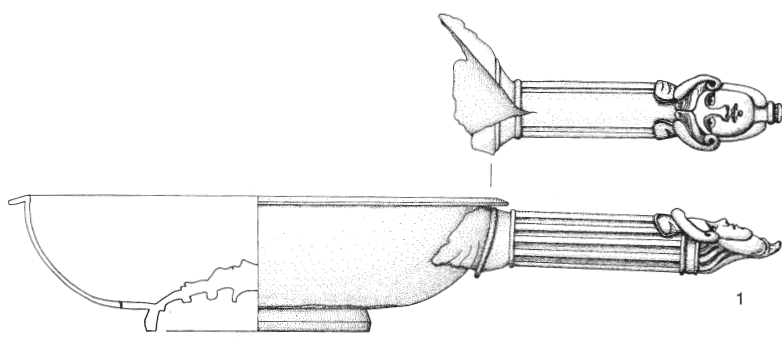

Abb. 23. Zell am See, Bronze-Griffschale, nach Sedlmayer 1999, Taf. 21.1 (s. Anm. 80).

Statt Griffschale: (Flache) Schale mit hülsenartig-zylindrischem Griff.

Statt Kelle/Sieb: Schale mit flachem, oft ruderförmigem Griff, leicht gerundetem Boden und Sieb.

Statt Kasserolle: Schale mit flachem Griff und flachem Boden.

Diese Begriffe wirken zwar sehr spröde und konstruiert, würden aber mehr Klarheit schaffen. Eine formale Ansprache sollte keine Funktion implizieren.

Als „Schöpfer“ möchte ich nur jene Objekte mit annähernd halbkugeliger Schale und vertikalem Griff bezeichnen. Ihre Form ist so eindeutig, dass man wohl von dieser Funktion ausgehen kann (Abb. 24). Sie ähneln unseren heutigen Suppenschöpfern und haben meiner Meinung nach weder mit Kellen noch mit Kasserollen funktionelle Gemeinsamkeiten. Konsequenterweise müsste man sie im Grunde als Schale mit vertikalem Griff bezeichnen.

\section{Funktion der Kasserollen}

Eine Möglichkeit, die Form der Kasserolle zu definieren, wäre folgende: Kasserollen haben tiefe Gefäßkörper mit ausgebauchten oder konischen, meist unverzierten Außenwänden. Die flachen Griffe von Silberkasserollen weisen auf ihren Oberseiten oft (figürliche oder pflanzliche) Reliefzier auf. Bei solchen aus Bronze ist dies selten, ihre Griffe sind häufig durchlocht. Die Böden von Kasserollen sind flach oder leicht nach oben gewölbt.

wirrung sorgen; Kritik soll eigentlich bei sich selbst beginnen: Bei den Abbildungen wurde aufgrund eines Kommunikationsfehlers die Kasserolle irrtümlich als Griffschale tituliert: IGL-WeBER, s. Anm. 61, 263 ff.

72 Radnoti, s. Anm. 31, $68 \mathrm{f}$

73 Nuber, s. Anm. 69. 

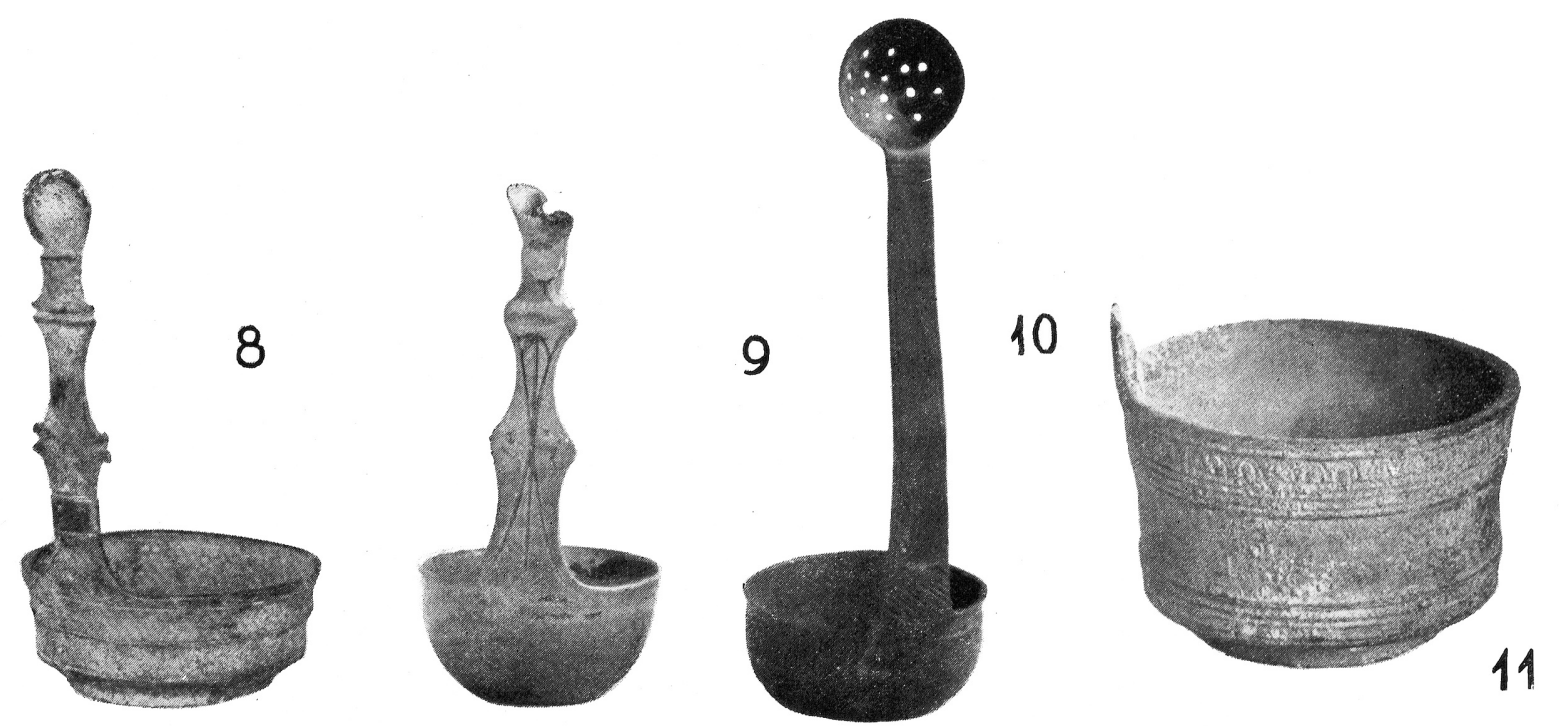

Abb. 24. Savaria, Brdovci, Siscia, Carnuntum, Schöpfer, nach Radnoti 1938, Taf. 28.8-11 (s. Anm. 31).

Besonders die Funktion der Kasserollen ist unklar. Zum Trinken wird man Kasserollen kaum verwendet haben. Man würde aufgrund des großen Durchmessers der Kasserollen wohl mehr Wein verschütten als trinken. Als Trinkgeschirr liegen ohnehin genügend variantenreiche Becherformen vor. Meist werden Kasserollen von der Forschung als Weinschöpfgefäße interpretiert:

R. Petrovsky meint zu den Kasserollen ${ }^{74}:$, ,. . ihre Funktion ist nicht restlos geklärt. ... dass sie zum Trinkservice gehören, wird auch durch das Vorhandensein des Weißmetallüberzugs unterstrichen."

Die Darstellung am Griff dieser meist schöpferähnlichen Form könne, wie allgemein angenommen wird, auf eine sakrale Funktion hindeuten, und zwar als Spendegefäß gerade an die Gottheiten, deren Attribute dargestellt sind. R. Petrovsky meint, Kasserollen mit niedrigerem Gefäßkörper haben zum Schöpfen von Wein gedient ${ }^{75}$. Die mit einem höheren Aufbau seien Mischgefäße gewesen.

Man kann sich m. E. ein Schöpfen aus einem Eimer oder Krater (Hochformen) mit beiderlei Formen nur schwerlich vorstellen. Entweder taucht dabei die Hand am Griff in die Flüssigkeit ein, was wohl nicht erwünscht war. Oder man hält die Kasserolle schief in die Flüssigkeit, somit kann das Gefäß aber maximal halb befüllt werden. Wir sehen also, dass der kurze, horizontale Griff der Kasserollen, egal, ob mit hohem oder niedrigem Becken, gegen die Funktion des Schöpfens spricht. Besonders, wenn sich in einem Mischgefäß nur noch wenig Flüssigkeit am Boden befand, ist an ein Schöpfen mit einer Kasserolle nicht zu denken. Man müsste dabei mit dem Arm förmlich in den Krater/Eimer hineinschlüpfen, was sehr umständlich und wenig ästhetisch wäre. Kasserollen mit niedrigem Gefäßkörper als Weinschöpfer zu betrachten, erscheint also wenig plausibel ${ }^{76}$.

Und weiters postuliert R. Petrovsky, Kasserollen mit hohem Gefäßkörper seien Mischgefäße $\mathrm{e}^{77}$ : "zum Schöpfen ungeeignet... Sie dienten am Tisch als Mischgefäße, in denen Wein, Wasser und Gewürze vermischt und nachher in Trinkbecher gegossen oder geschöpft wurden." Aus dem Krater oder Eimer geschöpft, folgte demnach ein anschlieBendes Mischen des Weines mit Wasser in der Kasserolle, mit der man dann erst den Becher befüllt haben soll. Dazu dienten aber m. E. Kratere/Eimer, die Mischgefäße schlechthin. Ein erneutes Mischen in einer Kasserolle wirkt doch sehr umständlich und überflüssig. Neben R. Petrovsky meint aber auch S. Künz ${ }^{78}$ : „Schöpfgefäße mit flachen Griffen, nach modernen Parallelen als Kasserollen bezeichnet, gehörten wahrscheinlich auch zum Trinkgeschirr...".
4 Petrovsky, s. Anm. 32, 91.

Petrovsky, s. Anm. 32, 34.

6 Auch Karasova, s. Anm. 71, 37 f. schließt sich Petrovsky an.
77 Petrovsky, s. Anm. 32, 106 ff.

78 KünZL, s. Anm. 24, 17. 
Aber zum Schöpfen sind m. E. Objekte mit vertikalem Stiel/Griff, wie unsere heutigen Suppenschöpfer, doch viel besser geeignet. Und genau solche sind ja in großer Zahl aus der Antike auf uns gekommen (Abb. 24). Gerade in diesem Zusammenhang ist eine Bemerkung von E. Weber interessant ${ }^{79}$ : Das Wort „Simperl“ existierte bis in jüngste Zeit im wienerisch-niederösterreichischen Dialekt und bezeichnete ein kleines Fässchen mit senkrechtem Griff, mit dem am Waschtag Wasser oder Lauge geschöpft werden konnte. Dieser etymologische Bezug wäre m. E. ein indirekter Beleg dafür, dass man diese echten Schöpfer mit vertikalem Griff in der Antike als simpulum bezeichnete, nicht aber Kasserollen. W. Hilgers bestätigt dies, wie oben behandelt.

Auch H. Sedlmayer geht nicht von einer Funktion als Kochgeschirr aus ${ }^{80}$. Sie widmet ein größeres Kapitel Funktionsfragen $^{81}$ der norischen Bronzegefäße und legt konkrete Befunde vom Magdalensberg vor, etwa Komplex OR/19: er enthält zwei Deckelkrüge, Kelle und Sieb, zwei Kasserollen (PetrovskyV, 1) sowie einen Teller. Dazu zählen noch 13 Sigillataschalen und 17 Sigillatateller. Diese Objekte kamen rund um einen Ofen beim Versturz der Mauern zu liegen und werden als Inventar einer Taberna gedeutet. Wir sehen hier Kelle und Kasserollen eindeutig im Kontext mit Essgeschirr.

H. Sedlmayer verweist weiters auf das häufige Vorkommen von simpula auf dem Magdalensberg, während diese Gefäßform, also Schöpfer mit vertikalem Griff, im suebischen Bereich fehle. Demgegenüber falle die große Zahl der im germanischen Bereich gefundenen Kasserollen in Kombination mit Eimern auf. Aus diesen Ensembles auf die ursprüngliche, römische Funktion der Einzelgefäße zu schließen, hält sie für problematisch.

J. Kunow bespricht neue Kombinationsmuster im germanischen Bereich ${ }^{82}$. Die Mutation des Kocheimers zum Trankeimer im Kontext mit Kelle/Sieb und Trinkgefäß wird als „Barbarisierung“ des ,römischen Leitbildes“ angesprochen. Insofern sei es problematisch, aus derartigen Kontexten stammende Inventare hinsichtlich ihrer ursprünglichen Funktionalität auf Reichsboden zu interpretieren. Aber selbst wenn Kasserollen in Kombination mit Eimern wirk-

80 H. Sedlmayer, Die römischen Bronzegefäße in Noricum, Monographies Instrumentum 10, Montagnac 1999, 84 ff. Kasserollen „eignen sich sowohl zum Schöpfen von Flüssigkeiten als auch durch die eingravierten Inneneinteilungen zum normierten Bemessen von Mengen." Letztere Funktion ist m. E. aber kaum als die ursprüngliche vorstellbar. lich dem „,barbarisierten“ Schöpfen/Trinken im germanischen Bereich gedient haben sollten, spricht dies m. E. nicht dagegen, dass Kasserollen in den Provinzen als Kochgeschirr verwendet wurden.

Andere germanische Grabfunde hingegen machen die Funktion der Kasserollen als Kochgeschirr sehr wahrscheinlich. Etwa sind sie häufig mit Trinkhörnern vergesellschaftet. Die Kasserollen scheinen hier einerseits wegen ihres großen Durchmessers besonders ungeeignet, um damit Wein zu schöpfen bzw. einzufüllen, andererseits wäre die vollständige Ess- und Trankbeigabe nicht komplett ohne Essgeschirr. Als Beispiel sei hier erneut auf das Grab II von Marwedel verwiesen $^{83}$.

Speziell bei Silberkasserollen vertritt auch S. MartinKilcher die Meinung, sie hätten nicht als Kochgeschirr gedient $^{84}$ : „Zwischen Trinkgeschirr und Ess- bzw. Auftraggeschirr sind die Kasserollen bzw. Kellen und/oder Sieb platziert, von denen ein Teil im Zusammenhang mit den Trinksitten gebraucht worden sein dürfte." Was aber liegt „zwischen Trinkgeschirr und Ess- bzw. Auftraggeschirr"? Und vor allem, welcher Teil von Kasserollen bzw. Kellen und/oder Sieben könne nun mit den Trinksitten in $\mathrm{Zu}$ sammenhang gebracht werden? S. Martin-Kilcher weiter: „Gegen eine Interpretation der Kasserollen als Bratgeschirr sprechen die Stücke aus Silber und Glas.“

Hier muss man aber anmerken, dass die meisten Kasserollen aus Bronze sind und sich somit durchaus zum Kochen eignen. Es gibt darüber hinaus ja auch solche aus Ton, die ebenfalls alltagstauglich sind. Es ist ungünstig, die selteneren Kasserollen aus edlen Materialien wie Silber oder Glas, also Luxusvarianten des Grundtyps, zur Beantwortung der Frage nach der ursprünglichen Funktion heranzuziehen. Ein weiterer Aspekt ist hier wichtig: Silberkasserollen tragen in Relation weitaus häufiger als die aus Bronze Abbildungen von Göttern und/oder deren Attribute bzw. Weihinschriften auf den Griffen. Solche Kasserollen aus Silber oder Glas kamen wohl eher im Rahmen von Kulthandlungen bzw. Kultmählern zum Einsatz. Folgerichtig müssen diese auch nicht sonderlich alltagstauglich gewesen sein. Man gestatte folgenden Vergleich: Die prächtigen Eucharistie-Kelche, die im Rahmen christlicher Messen auch heute verwendet
81 Sedlmayer, s. Anm. 80, $129 \mathrm{ff}$.

82 J. Kunow, Der römische Import in der Germania libera bis zu den Markomannenkriegen, Göttinger Schr. z. Vor- u. Frühgesch. 21, 1983, 80f.

83 Laux, s. Anm. 18, 315 ff.

84 S. Martin-Kilcher, Römisches Tafelsilber. Form- und Funktionsfragen, in: Cahn, Kaufmann-Heinimann, s. Anm. 7, 393 ff. 
werden, kommen auch nicht beim alläglichen Weintrinken (etwa im Wirtshaus) zum Einsatz. Dennoch trinkt man daraus.

Ein weiteres Argument in diese Richtung ist die Durchlochung der meisten Griffenden von Bronzekasserollen: Man konnte sie an die Wand hängen, wie es in vielen Küchen bis heute praktiziert wird. Es war Alltagsgeschirr des gehobenen römischen Haushalts und durchaus zum Kochen geeignet. Silberkasserollen zeigen selten Durchlochung; derartige Luxusware (oder eben Kultgerät) hing nicht an der Wand, sondern wurde wohl entsprechend verwahrt.

Folgende Argumente sprechen nun für eine Funktion von Kasserollen als Kochgeschirr:

1. Wichtig ist die Herkunft der Kasserolle selbst. Es gilt seit A. Radnotis typologischer Gliederung als allgemein anerkannt, dass sich die römischen Bronzekasserollen aus sehr flachen Formen, Pfannen entwickelt haben. Diese sind völlig ungeeignet um damit Flüssigkeiten zu schöpfen. Diese Entwicklung der Kasserollen aus flachen Formen führt doch recht gut vor Augen, welche Funktion sie innehatten. Eine Entwicklung von Pfanne zu Schöpfer ist doch wenig nachvollziehbar.

2. Der flache Boden spricht grundsätzlich für eine Funktion als Kochgeschirr. Die besonders auf Bronzekasserollen befindlichen Ringe auf den Bodenunterseiten, aber auch die oftmals nach oben gewölbten, abgesetzten Böden könnten einer besseren Temperaturverteilung gedient haben, egal, ob man die Kasserollen nun direkt in die Glut oder auf dreibeinige Untersetzer gestellt hat. A. Radnoti bildet eine Bronzekasserolle mit entsprechender Bodengestaltung $\mathrm{ab}^{85}$ (Abb. 25). Dies sollte möglicherweise die Speisen von allzu großer Hitze fernhalten, schützen. Bei Schöpfgefäßen wäre eine derartige Bodengestaltung überflüssig.

3. Weiters kann man die Griffgestaltung heranziehen. Kasserollen, sowohl solche aus Bronze, Keramik, aber auch aus Silber, weisen Verzierung fast ausschließlich auf ihren Griffoberseiten auf. Die Schalenaußenwände hingegen sind fast immer unverziert. Das vorliegende Stück aus Wieselburg stellt eine sehr seltene Ausnahme dar. Wenn Kasserollen nun als Schöpfer oder als Mischgefäß fungiert haben sollen, fragt man sich, weshalb sie oft so reich verziert sind. Denn diese Funktionen verrichteten in einem entsprechend gehobenen Haushalt Diener, was bildliche Darstellungen belegen. Gefäße, die dem bloßen Servieren des Weines dienten, waren den alten Römern. Eine Kulturgeschichte des Essens und Trin-

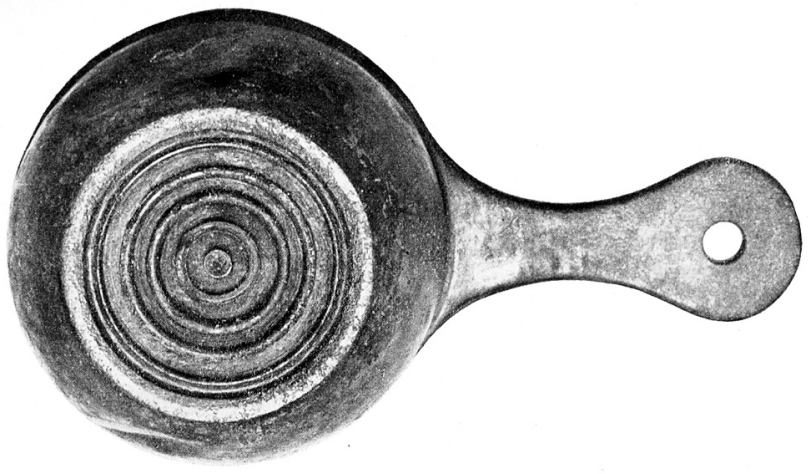

Abb. 25. Sirmium, Bronzekasserolle, nach Radnoti 1938, Taf. 22.1b (s. Anm. 31).

folglich nicht als repräsentative Schauobjekte bei Tisch, sondern eher „Funktionsgeräte“. Gerade die so reich verzierte Griffoberseite der Kasserolle wäre in der Funktion als Schöpfgefäß somit von der Hand des Dieners (oder wem auch immer) verdeckt gewesen, was doch sehr verwundert. Günstiger erscheinen auch hierbei Schöpfer mit vertikalem Griff, sie sind äußerst selten reich verziert, ,,simple“ Objekte (simpula).

4. Wenn man nun argumentiert, Kasserollen wären bei den Tafelnden gestanden, so frage ich mich, weshalb ihre Außenwände so auffallend unverziert waren. Im krassen Gegensatz dazu waren die (bei den Speisenden/Trinkenden befindlichen) Trinkbecher gerade an ihren Außenwänden am reichsten verziert, genauso wie Kratere oder Eimer. Man kann also davon ausgehen, dass die oft reich reliefverzierten Griffoberseiten der Kasserollen bei Tisch gesehen werden sollten, und eben speziell diese; während die unverzierte Gefäßaußenwand weniger im Mittelpunkt, Blickfeld der Tafelnden stand.

Ein Vorschlag zur Funktion: Die vergleichsweise kleinen Kasserollen könnten zum Auftragen, Servieren insbesondere aber Warmhalten von vorgekochten und -geschnittenen Speisen gedient haben, etwa in Kohlebecken auf die Tafel gestellt, ähnlich unserem Fondue-Essen (Abb. 26 a, b) ${ }^{86}$, wenn auch beim Fondue ja eigentlich gekocht wird. Die Randgestaltung solcher Kohlebecken verleiht der Kasserolle zusätzliche Standfestigkeit, die Griffe der hineingestellten Kasserolle(n) werden abgestützt.

Das Warmhalten von Gerichten bei Tisch ist in unserer heutigen Küche eher unüblich geworden, während sich fast

kens, Arch. Deutschland, Sonderheft, 2001, Abb. 24. G. Gerlach dazu: „Solche Kohlebecken dienten als Wärmequelle... aber auch zum Wärmen von Speisen." 


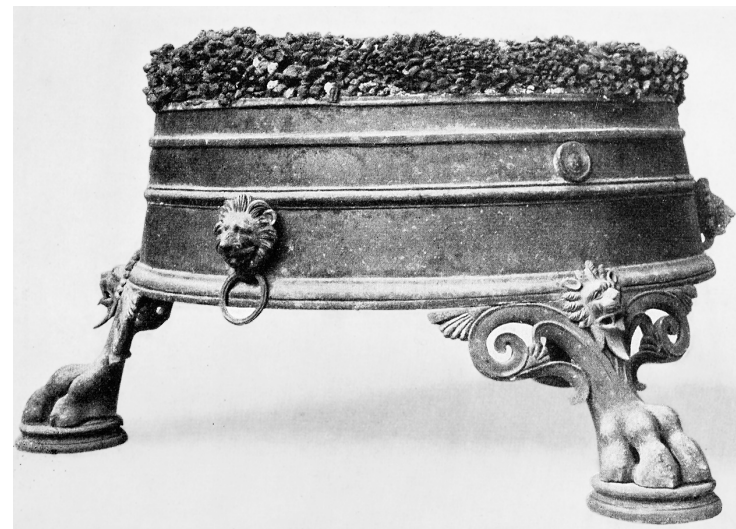

Abb. 26a. Pompeji, Bronzebecken, nach Maiuri 1932, Fig. 164 (s. Anm. 23).

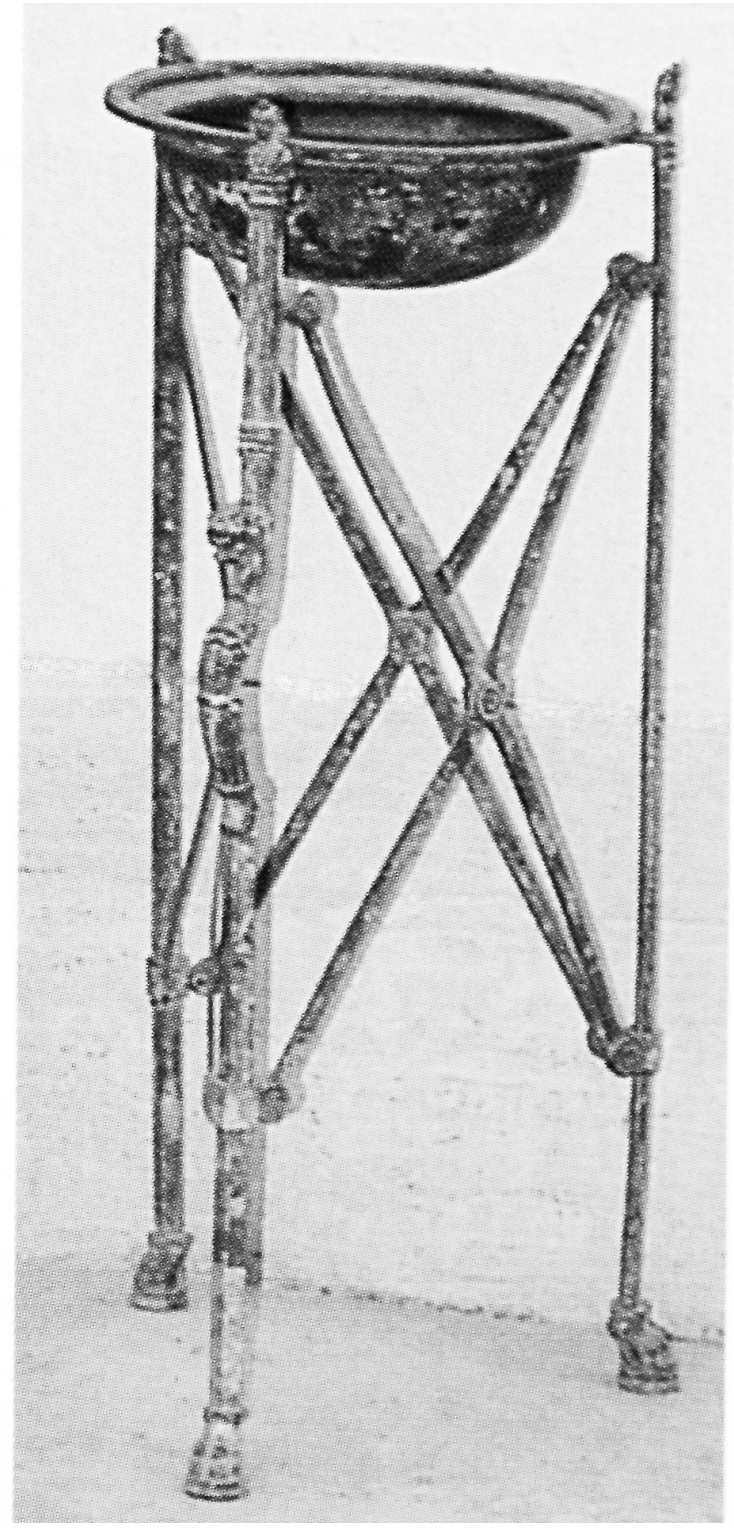

Abb. 26b. Rom, Bronzebecken, nach Gerlach 2001, Abb. 24 (s. Anm. 86).

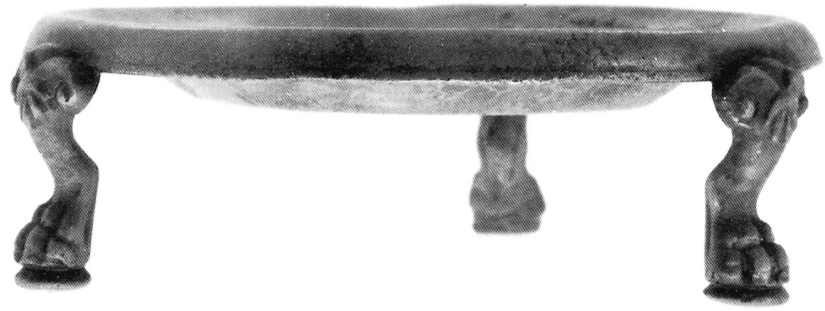

Abb. 27. Lazarevac, Dreibeingestell aus Silber, nach Popovic 1994, Nr. 153 (s. Anm. 49).

food großer Beliebtheit erfreut. Somit könnte man auch erklären, weshalb diese Funktion auf den ersten Blick so exotisch auf uns wirkt. Anders hingegen etwa im asiatischen Bereich: Man positioniert Serviergeschirr mit den darin befindlichen Speisen zum Warmhalten bei Tisch auf kleine Gestelle, in denen Kerzen brennen.Vor diesem Hintergrund kann man sich gut vorstellen, dass dies auch römische Sitte gewesen sein mag. Die Hitze in solchen Kohlebecken musste nicht groß gewesen sein. Es reicht eine sehr geringe Menge Glut, um das Essen auch längere Zeit bei Tisch zu wärmen und gleichzeitig die Rauchentwicklung bei Tisch gering zu halten. Besonders, wenn man in die eigentliche Glut kleine Gestelle, vielleicht die Dreibeine (tripes) als Untersetzer stellte ${ }^{87}$, konnten selbst Kasserollen aus hitzeempfindlicheren Materialien, wie etwa Glas, darauf ruhen, ohne den geringsten Schaden zu nehmen (Abb. 27). Mit Löffeln oder mit den Fingern aß man - wie in der Antike üblich ${ }^{88}$ - daraus die bereits vorgeschnittenen Stücke.

In diesem Kontext sind auch die mittelalterlichen bis neuzeitlichen Dreibeinpfannen interessant, etwa aus dem Gebiet des heutigen Deutschland ${ }^{89}$. In diesem Gefäßtyp könnte man die funktionale Zusammengehörigkeit von römischer Kasserolle und dreibeinigem (Glut-)Untersetzer erkennen. Wenn dieserVergleich auch methodisch unorthodox erscheinen mag, erlaubt die eindeutige Funktion dieser Gefäßform vielleicht dennoch Rückschlüsse auf die der römischen.

Wenn nun die Kasserollen in Kohlebecken hineingestellt wurden, waren die Gefäßwände nur teilweise sichtbar, was ihre oben besprochene, häufige Verzierungslosigkeit erklären könnte. Man sah bei Tisch eigentlich nur die Griffoberseiten und die sind ja Träger des Dekors bei Kasserollen schlechthin.

Weniger glaube ich, dass sie als eigentliches Koch- oder Bratgeschirr auf dem Herd dienten. Dafür sind sie auch zu

87 Hilgers, s. Anm. 65, Hilgers stellt fest, dass die Dreibeingestelle direkt in die Glut gesetzt wurden.

88 Martin-Kilcher, s. Anm. 84, 397 ff.

89 T. Dexel, Gebrauchsgerättypen II, Darmstadt 1981, Abb. 122. 
klein. Dort kamen eher große Töpfe und Kessel aus verschiedenen Materialien zum Einsatz, auch einfache schmucklose Bratpfannen aus Bronze.

Man könnte nun entgegnen, dass diese Vorschläge zur Funktion der Kasserollen (Servieren, Warmhalten und Essen der Speisen) die Vorgänge bei den Mahlzeiten der Römer unnötig verkompliziere. Dagegen sei angemerkt, dass die wohlhabende römische Oberschicht wohl keine Kosten und Mühen für üppige Mahlzeiten scheute. Dies belegen verschiedenartigste literarische Quellen. Besonders Seneca wenn auch tendenziös - prägte das Bild des Römers als unersättlicherVielfraß, der mit der Feder Raum für weitere Gänge im Magen schaffen musste. Man denke ferner an die überlieferte Fisch- und Austernindustrie. Bildliche Darstellungen von üppigen Tafeln und ausgelassenen Speiseszenen ergänzen dies. Sogar die Architektur, vor allem die besondere Rolle, die man dem großen triclinium innerhalb des römischen Hauses beimaß, untermauert, welch hohen Stellenwert Mahlzeiten bei den Römern innehatten. Wir wissen, aus welch aufwändig verzierten, unterschiedlichen Gefäßformen teils kostbarster Materialien die Römer tranken. Wenn nun beim Essen nur große Platten, Teller und Schalen, wenn auch reich verziert, zum Einsatz gekommen sein sollten, so setzt dies voraus, dass das Essen bei Tisch kalt wurde. Da eine ausgiebige römische Mahlzeit sich über den ganzen Abend ausdehnen konnte (auch ohne Trinkgelage), wie uns die Literatur überliefert, kann man vermuten, dass man die Speisen über längere Zeit bei Tisch warm halten wollte. Etwa mit den auf uns gekommenen Kohlebecken (Abb. 26 a, b). Diese ausschließlich als Öfen zur Erhöhung der Zimmertemperatur zu deuten, scheint wenig nachvollziehbar. Es waren doch sogar in sehr bescheidenen römischen Wohnbauten in verschiedensten Provinzen Heizungen baulich integriert (von einfachsten Öfen bis zu Hypokaustanlagen). Solche Kohlebecken fungierten m. E. eher als mobile Warmhalte-Herde, die bei Tisch zum Einsatz kamen. Als Zweckform passt die Kasserolle (oder deren mehrere) gut hinein.

Man könnte nun fragen, ob die auf uns gekommenen Kasserollen - wenn sie als Kochgeschirr gedient haben sollten - Spuren von Hitzeeinwirkung aufweisen: Silberkasserollen etwa aus dem Fund von Boscoreale und der Casa del Menandro zeigen geringe Brandspuren, die von derartiger Hitzeeinwirkung stammen sollen $^{90}$. A. Maiuri

90 Nuber, s. Anm. 68, 115.

91 Maiuri, s. Anm. 23, 354.

92 Dembsкy, s. Anm. 41, 1992, 45. „Das Silber an der Außenseite weist eigentümliche Verfärbungen auf, die den Schluss nahe legen..., dass es öfter heiß gemacht worden sein könnte.“ postulierte bereits vor Jahrzehnten für eine Silberkasserolle mit entsprechenden Spuren aus der Casa del Menandro, dass es Kochgeschirr gewesen sein könnte ${ }^{91}$. Aber auch beim Neufund aus Lauriacum-Enns konnten eindeutige Spuren von Hitzeeinwirkung beobachtet werden ${ }^{92}$. Diese Brandspuren befinden sich am Boden und nur wenig darüber an der Außenwand der Schale, wie man in der linken Hälfte der Abbildung (Abb. 17) erkennen kann. Das Gefäß wurde also offenkundig in nur schwache Glut oder knapp darüber gestellt. Ein Schadensfeuer hätte am gesamten Gefäß Brandspuren hinterlassen, bzw. es gänzlich deformiert. Wir sehen, dass diese besprochenen Gefäße eher als Kochgeschirr, denn als Trinkgefäße gedient haben dürften. Dass entsprechende Brandspuren nur an wenigen Silberkasserollen zu beobachtet sind, ist verständlich: Erstens wurde dies, so weit ich sehe, kaum beachtet. Besonders Silberkasserollen wurden fast nie fachmännisch bei Grabungen geborgen, sondern traten wie gesagt als Grab- oder Hortfunde, auch von Raubgräbern gehoben, eher zufällig ans Tageslicht. Wer achtete da schon auf allfällige Rußspuren, viel eher war man geneigt, die Stücke sofort zu reinigen und vor allem zu polieren. Dabei gingen allfällige, geringe Brandspuren, die ein Warmhalten in schwacher Glut in einem Kohlebecken hinterlassen haben mögen, natürlich verloren. Besonders Silberobjekte, die ja rasch ihren Glanz verlieren, wurden selbst nachdem sie in (archäologische) Sammlungen gekommen waren, sicherlich mehrfach unfachmännisch scharf gereinigt, immer wieder poliert. Außerdem wurden Kasserollen als Vergrabungshorte oder auch als germanische Grabbeigaben wohl bereits antik gereinigt dem Boden übergeben. Entsprechende Metalluntersuchungen könnten weiterhelfen. Kasserollen sind m. E. aber auch als bloßes Servier- und Essgeschirr bei Tisch denkbar, also ohne Kohlebecken zum Erwärmen, das Brandspuren verursacht hätte. Das Fehlen solcher Spuren kann also nicht als zwingendes Argument für eine Funktion als Trink/Schöpfgefäß herangezogen werden.

Nur wenige haben die Kasserollen als Kochgeschirr angesprochen: D. E. Strong nennt Kasserollen saucepans. Er kann sich sowohl eine Verwendung als Trink- als auch Kochgeschirr vorstellen ${ }^{93}$. A. Radnoti schließt eine Funktion der Kasserollen als Kochgeschirr auch nicht aus ${ }^{94}$. H.-U. Nuber meint, Kasserollen seien „Allzweckgeschirr, das nicht als Trinkgeschirr fungierte..." ${ }^{\prime 95}$.

93 Strong, s. Anm. 37, 145 ff.

94 Radnoti, s. Anm. 31, 9 ff.

95 Nuber, s. Anm. 68, 181. 
Trinkgeschirr scheint mir - wie oben ausgeführt - wenig plausibel. Kasserollen waren aber m. E. auch kein echtes Koch- oder Bratgeschirr. Sie dürften als Ess- und Serviergeschirr gedient haben.

\section{Funktion der Kelle/Sieb-Garnituren}

H.-U. Nuber führt Argumente gegen den Gebrauch von Kelle und Sieb zum Weinsieben an, er meint, dieses Gefäßpaar diente als Kochgeschirr. Etwa zum Abtropfen des Öls vom Fleisch ${ }^{96}$, vergleichbar mit den heutigen Fondue- oder Pommes-frites-Töpfen.

H. Friesinger legt u. a. Fragmente von Kasserollen, und Kelle/Sieb-Garnituren vor, die er ebenfalls als Kochgeschirr anspricht ${ }^{97}$. Gegen eine Funktion von Kelle und Sieb als Weinschöpfgefäß sprechen seiner Ansicht nach besonders der horizontale Griff, der beim Schöpfen hinderlich sei. Andererseits verwundere auch die Absenz der Kelle/SiebGarnitur in römischen Gräbern, wo Trinkgarnituren an sich ja beigegeben wurden. Als weiteres Argument führt er an, dass allfällige dem Getränk beigefügte Zusätze als Bodensatz beim Schöpfen erst gar nicht aufgewirbelt oder schon vor dem Servieren entfernt worden wären. Wahrscheinlicher sei nach Friesinger eine Verwendung der Kelle/Sieb-Garnituren zur Fleischzubereitung. Das Sieb könne auch zum Abtropfen des Öls von gebratenen Speisen gedient haben, nicht zwingend dem Gewürzabseihen des Weines.

Als weiteres Argument in diese Richtung möchte ich anmerken, dass Kelle/Sieb-Garnituren kaum verziert sind. Sie sind meist aus Bronze, in Silber treten sie im Verhältnis zu Kasserollen viel seltener auf. Man ist geneigt, in ihnen eher Gebrauchsgeschirr des Alltags (natürlich nur im gehobenen Haushalt) als echte Repräsentationsobjekte wie etwa Silberkasserollen oder reliefverzierte Bronzekasserollen zu erkennen. Grundsätzlich ist der Vorschlag bezüglich Bratgeschirr sehr interessant. Ein Problem bleibt bestehen: die oft rundlichen Böden der Kellen. Sie stehen nicht von selbst, außer man würde sie etwa stark in die Glut drücken oder die Griffe so an den Rand des Ofens legen, dass sie nicht kippen. Ferner sind Kelle/Sieb-Garnituren (wie auch schon für die Kasserollen festgestellt) zu klein, um mit ihnen für einen Haushalt mit mehreren Personen zu braten (oder kochen).

Als Lösungsvorschlag möchte ich anfügen, dass Kelle/ Sieb-Garnituren auch als Seih- und Auftraggeschirr für gekochte Fleischspeisen, also weniger als eigentliches Kochgeschirr fungiert haben könnten. Die Verbreiterungen, die oft in der Mitte der ruderförmigen Griffe von Kelle/SiebGarnituren anzutreffen sind, könnten dazu gedient haben, dass man sie etwa von den Rändern/Henkeln großer Töpfe/Kessel in ebendiese hineinhängen lassen konnte, ohne dass sie hineinfielen. Außerdem liegen sie so besser in der Hand, man kann mit Daumen und Zeigefinger den Griff gut umschließen. Die im Verhältnis sehr langschmalen Griffe der Kellen (im Gegensatz zu den tendenziell etwas kürzeren Kasserollengriffen) könnte man dahingehend interpretieren, dass so allzu große Hitze (des Ofens oder Topf/Kessel) von der Hand ferngehalten werden sollte. Die langschmalen Kelle/Sieb-Griffe leiten Hitze kaum.

Gekochte Fleischstücke konnte man mit dem Sieb selbst aus hochformatigen Töpfen heben, „fischen“. Man muß sich den Vorgang bildlich vorstellen: Das Heben von festen Stücken auch aus hohen Töpfen funktioniert mit Geräten mit horizontalen Griffen sogar besser als mit Schöpfern mit vertikalen Griffen. Mit letztgenannten hätte man nämlich Schwierigkeiten, aus einer Hochform innen am Boden befindliche Stücke herauszunehmen. Beim Flüssigkeit- oder Weinschöpfen aus Hochformen wie Krater oder Eimer verhält es sich genau umgekehrt. Mit dem Sieb abgeseiht, servierte man die Speisen, sei es nun gekochtes oder gebratenes Fleisch, in den bei Tisch befindlichen Kasserollen oder auf Platten und Teller. Die unter das Sieb gehaltene Kelle fing möglicherweise beim Transport (aus der Küche zur tafelnden Runde) abtropfende Flüssigkeiten (Öl oder (Salz-)Wasser) auf.

Dieser Exkurs zur Funktion von Kelle/Sieb sollte jedenfalls zeigen, dass auch diese Gefäßkombination nicht zwingend als Trinkgeschirr interpretiert werden muß.

\section{Bildliche Darstellungen von Kasserollen}

Wenn wir die Funktion der Kasserollen klären wollen, helfen auch bildliche Darstellungen in Mosaik und Wandmalerei. Ein berühmtes Beispiel ist das Wandgemälde aus der Nekropole von Pompeji mit der Darstellung eines Silberservices (Abb. 28). Alle Gefäße, außer dem Mischkrug, sind paarweise vorhanden. Im Vordergrund sieht man eine Kanne mit Griffschale. Wir treffen wieder auf vier Schöpfer mit senkrechten Griffen, deren Enden umgebogen sind. Man konnte die Schöpfer so an den Rand des Mischgefäßes hängen. Wenn dieses Fresko auch wesentlich älter ist als unsere Kasserolle, so muss festgehalten werden, dass mehrere Silberkasserollen aus Pompeji auf uns gekommen sind. 


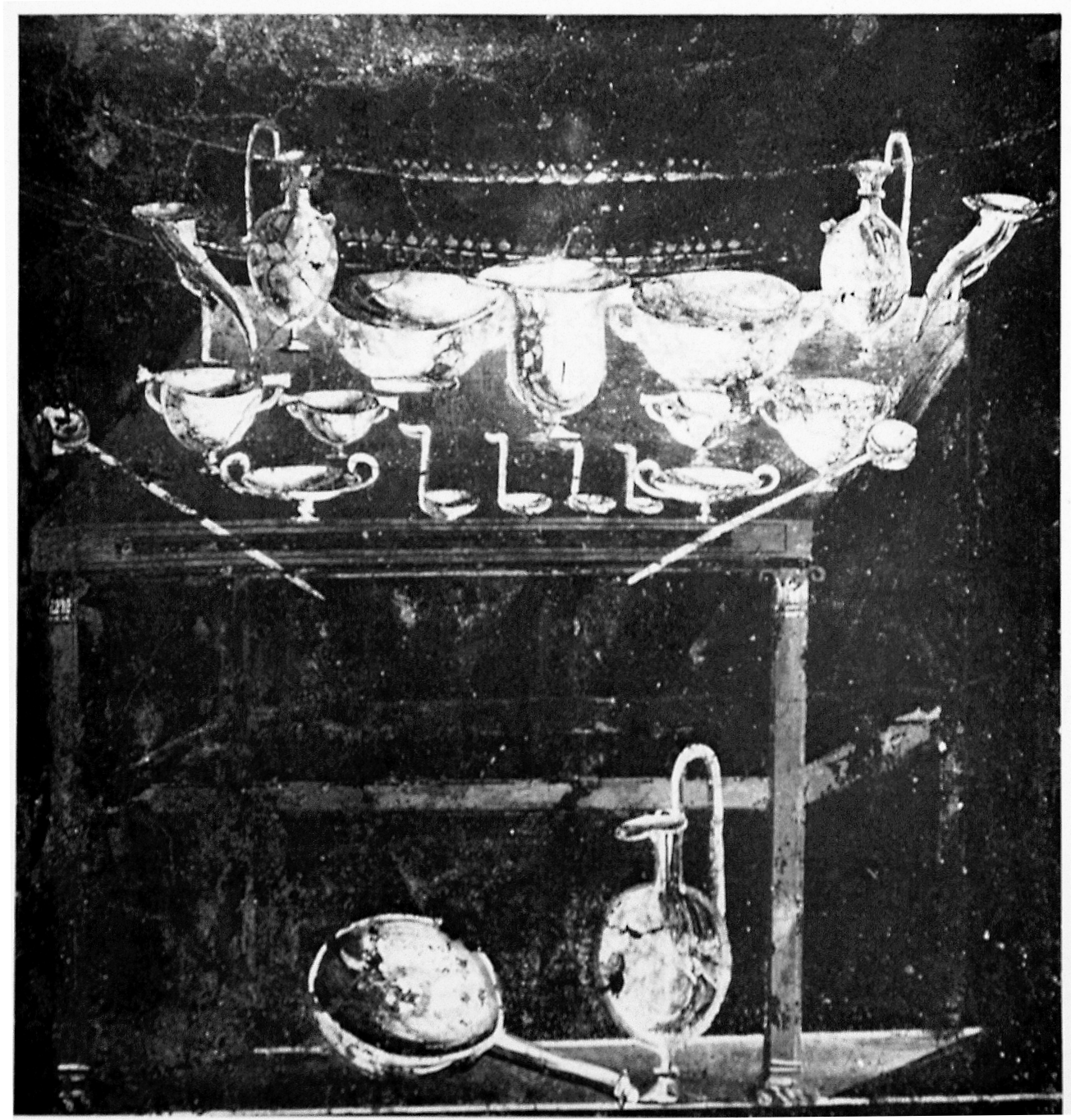

Abb. 28. Pompeji, Wandgemälde, nach Hilgers 1969, Taf. 5 (s. Anm. 65).

Von Kasserollen, Essgeschirr allgemein, fehlt im Fresko hingegen jede Spur.

Wichtig ist, dass bei den häufig in Mosaik und Wandmalerei dargestellten Trinkszenen Kasserollen - so weit ich sehe - nicht auftauchen. Sie zeigen sich aber in den verhältnismäßig selten dargestellten Mahlzeitszenen. Auch hier liegt eine Darstellung aus Pompeji vor: ein Fresko, das eindeutig eine Mahlzeit, wohl in einem Wirtshaus, abbildet. Hier erscheint - schlecht zu erkennen - eine Kasserolle auf dem Tisch ${ }^{98}$. Die speisende Person links außen hält ein Gefäß in der rechten Hand, das entweder eine Kasserolle oder eher eine Kelle sein könnte; diese Gefäße werden hier jedenfalls nicht als Trinkgeschirr verwendet.

98 Gerlach, s. Anm. 86, Abb. 16.

99 D. Levi, Antioch Mosaic Pavements, 1971, 132 ff., Taf. 24
Als weiteres Beispiel sei hier ein schönes Mosaik aus Antiochia (Abb. 29) angeführt ${ }^{99}$ : Es zeigt den Ablauf einer Mahlzeit, rechts oben gustatio: Eier und Früchte als Appetitanreger, es folgt die eigentliche Hauptspeise, die cena oder primae mensae: Fisch und Schinken, serviert auf groBen Platten. Nach diesen salzigen Speisen folgt ein Trinkbecher. Weiters sehen wir Geflügel mit Brot. Mit Süßspeisen wie Früchten oder Kuchen wurde das Mahl beendet. Dieser Nachtisch, belloria oder auch secundae mensae konnte gegebenenfalls in eine comissatio, ein Zechgelage übergehen.

Wichtig sind hier die beiden Silbergefäße, welche die Szene oben umrahmen. D. Levi schlägt vor, diese paterae ${ }^{100}$

100 Auch hier wird der wohl falsche lateinische Begriff patera auf die Kasserollen bezogen. 


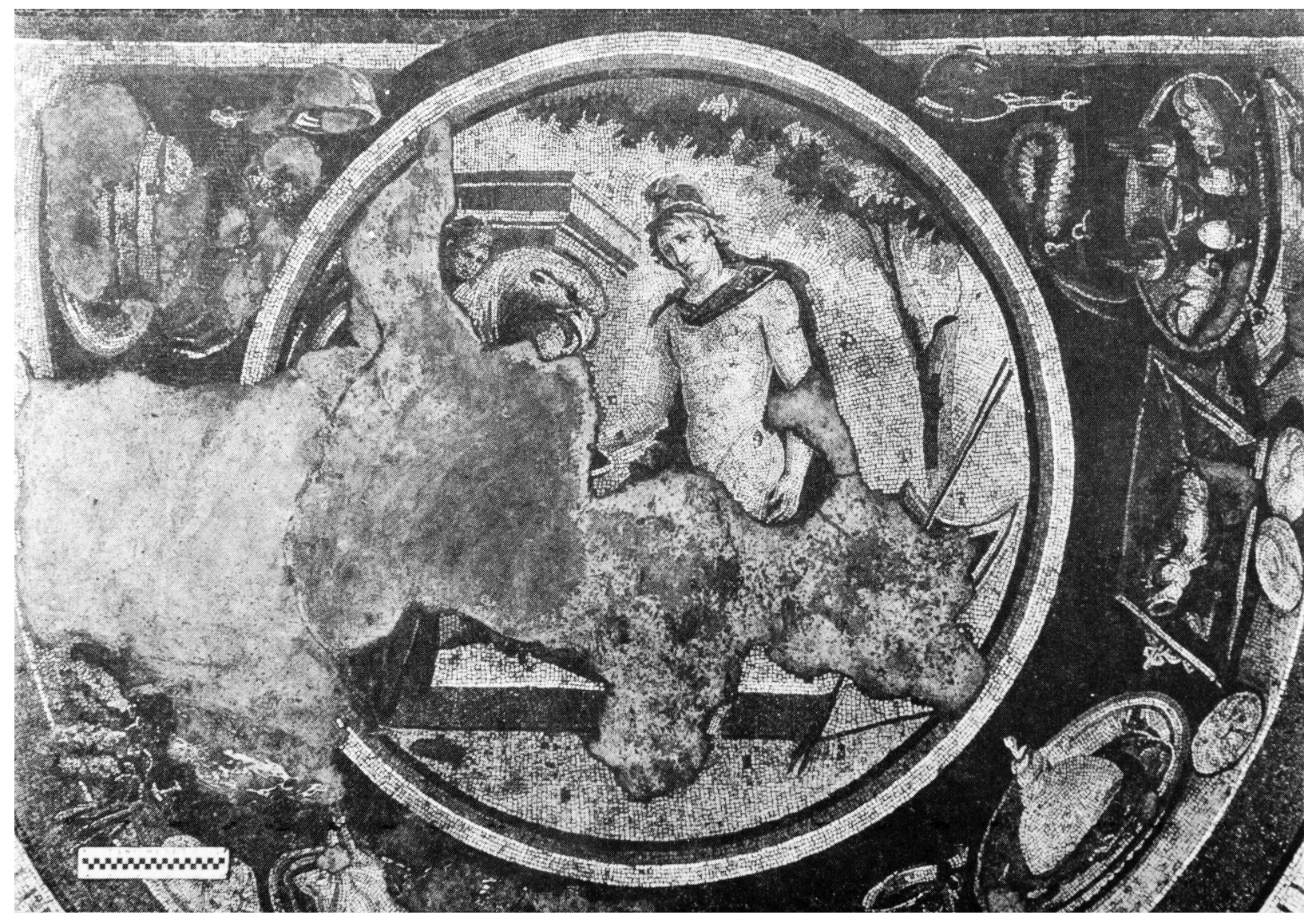

Abb. 29. Antiochia, Mosaik, nach Levi 1971, Taf. 24 (s. Anm. 99).

als Serviergefäße für heiße Gerichte zu verstehen, die man so transportierte und auf die großen Platten legte. Wir sehen jedenfalls, dass diese Gefäße in Rahmen der cena, der Mahlzeit und nicht im Rahmen des Trinkgelages zum Einsatz kamen. Dabei wurde zwar auch getrunken, wie der abgebildete Becher belegt. Man könnte nun argumentieren, dass die Kasserollen mit Wein gefüllt bei Tisch standen, sozusagen zum Nachfüllen der Becher. Dies verrichteten im Rahmen solch luxuriöser Tafeln eher Diener direkt aus dem Krater. Bildliche Darstellungen zeigen Diener mit Bechern in der Hand, im Begriff, diese abseits der Tafel wieder zu befüllen (Abb. 31). Wichtig ist auch eine Darstellung aus Spanien ${ }^{101}$ (Abb. 30): Wir sehen in dem umgezeichneten Mosaik ein Objekt, dass man als Grillrost interpretieren möchte. Rechts davon eine Kasserolle, eher aber eine Kelle mit langem Griff, also Kochgeschirr. Neben Rost und Kochgeschirr befindet sich ein Kohlebecken samt Blasebalg. Zwei Kasserollen sind

101 J.-M. Blazquez, Mosaicos Romanos de Cordoba, Jaen y Malaga, Corpus de Mosaicos de Espana 3, 1981, Taf. 62-66, Fig. 22/23. im Sektor 1 dargestellt. In Reihe 4 sieht man ein großes Mischgefäß, an dessen Rand ein Schöpfer mit vertikalem Griff hängt. Wein schöpft man auch hier eindeutig nicht mit Kasserollen oder Kellen.

Auf einem Relief aus Neumagen ${ }^{102}$ (spätes 2. Jh. n. Chr.) sieht man einen Mundschenk, der im Begriff ist, einen Becher zu befüllen. Auf der Anrichte, abseits der eigentlichen Tafel, steht im Hintergrund u.a. Trinkgeschirr in sehr flachem Relief (Abb. 31) und eine Kasserolle. Darin befindet sich ein weiteres Objekt, das stark verschliffen ist. Kann man möglicherweise einen Fisch, mit Kopf nach links und Schwanzflosse in bzw. neben der Kasserolle erkennen? Wie dem auch sei, auch diese Kasserolle hat nicht als Schöpfgefäß gedient, sie würde unmöglich durch den engen Hals des Mischgefäßes im Hintergrund passen.

Von großer Bedeutung ist hier der "Mahlzeitgiebel“ aus dem 3. Jh., ebenfalls aus Neumagen, heute im Rheini-
102 R. SCHINDLER, Führer durch das Landesmuseum Trier, Trier 1977 Abb. 177. 


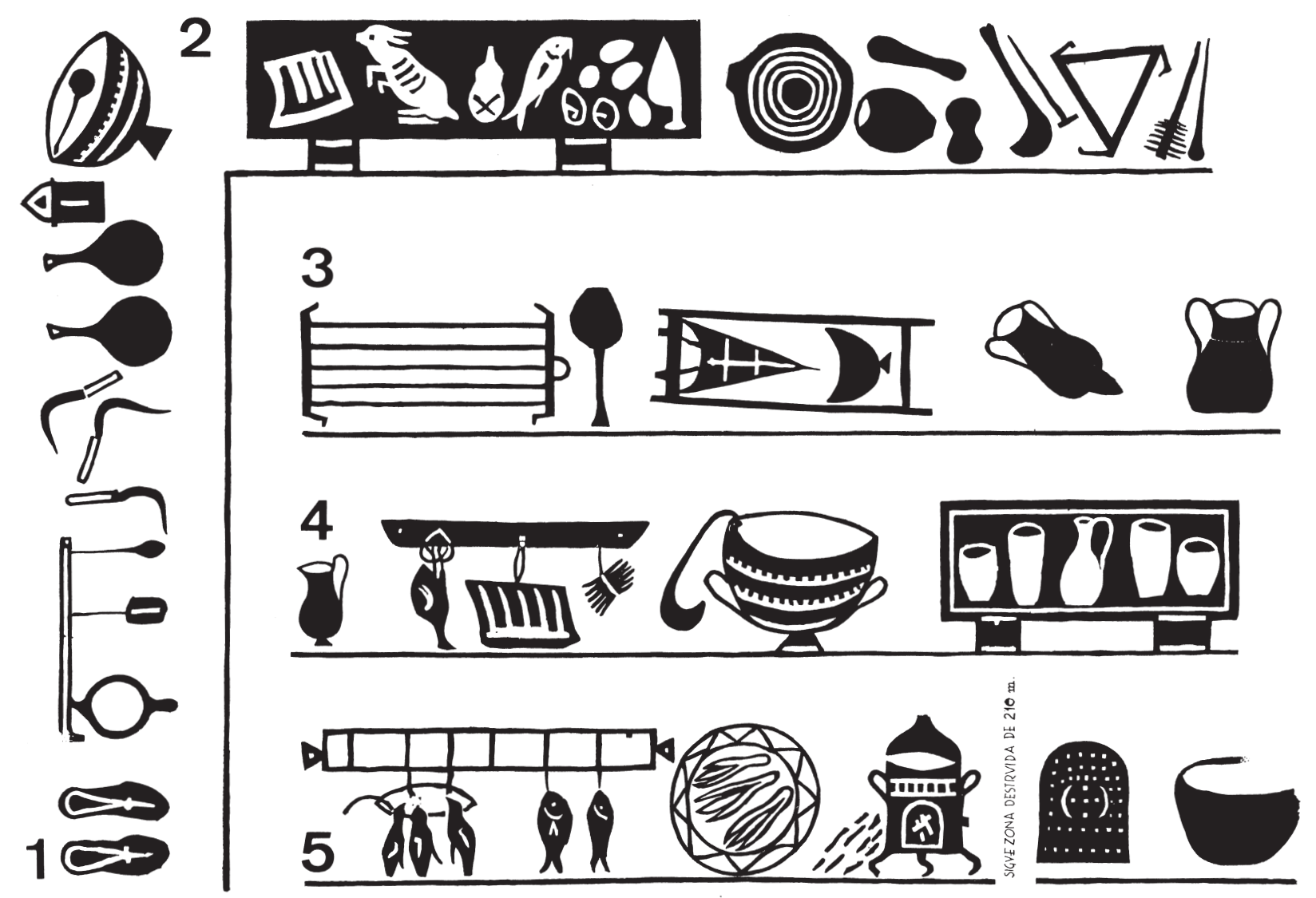

Abb. 30. Marbella, umgezeichnetes Mosaik, nach Blazquez 1981, Fig. 23 (s. Anm. 101).

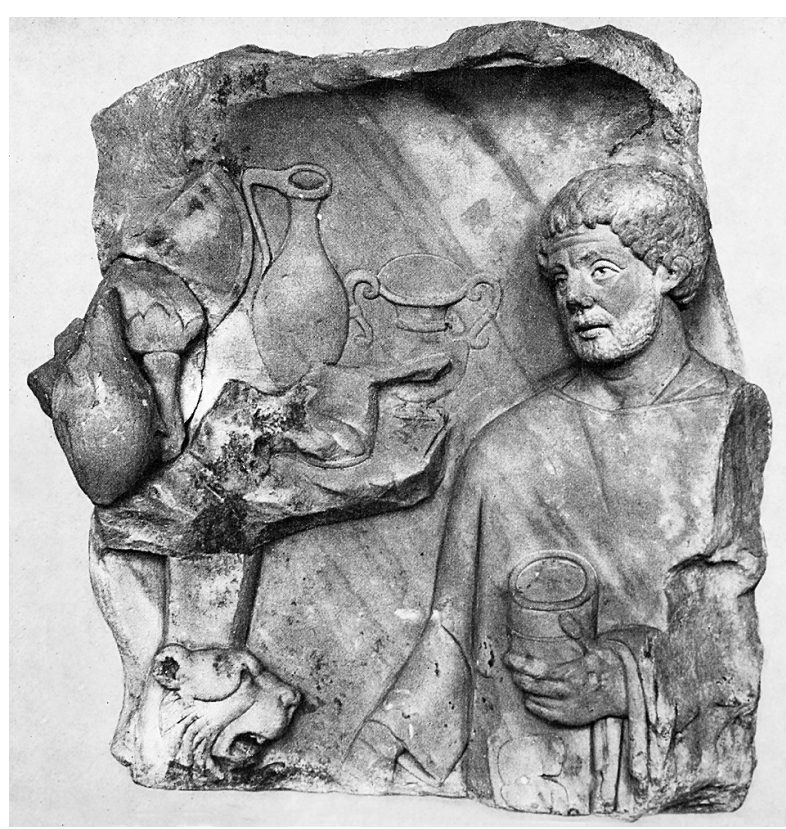

Abb. 31. Neumagen, Relief, nach Schindler 1977, Abb. 177 (s. Anm. 102). schen Landesmuseum Trier ${ }^{103}$ (Abb. 32). Eine Person hält eine Kasserolle in der Rechten und streckt sie dem Tischnachbarn entgegen, dem suggerierend, doch etwas herauszunehmen. Wein und Wasser hingegen werden mit Objekten mit vertikalen Griffen aus großen Krügen geschöpft, die neben dem Tisch am Boden stehen. Eine Frau hält in ihrer Rechten einen Trinkbecher. Diese Darstellung lässt m. E. kaum Zweifel über die Funktion der Kasserolle zu.

Ein mittelalterlicher Passionsaltar aus dem 14. Jh. in der Niedersächsischen Landesgalerie Hannover (Abb. 33) zeigt rechts eindeutig einen Fischschwanz aus einer Kasserolle ragen ${ }^{104}$. Die Tatsache, dass die Darstellung aus dem Mittelalter stammt, ändert nichts an der grundsätzlich zeitlosen Funktion dieser Geschirrform als Ess- bzw. Serviergeschirr. Um mit einer Frage zu schließen:

Ist es reiner Zufall, dass viele der römischen Kasserollengriffe in Form von Fischschwänzen enden? 


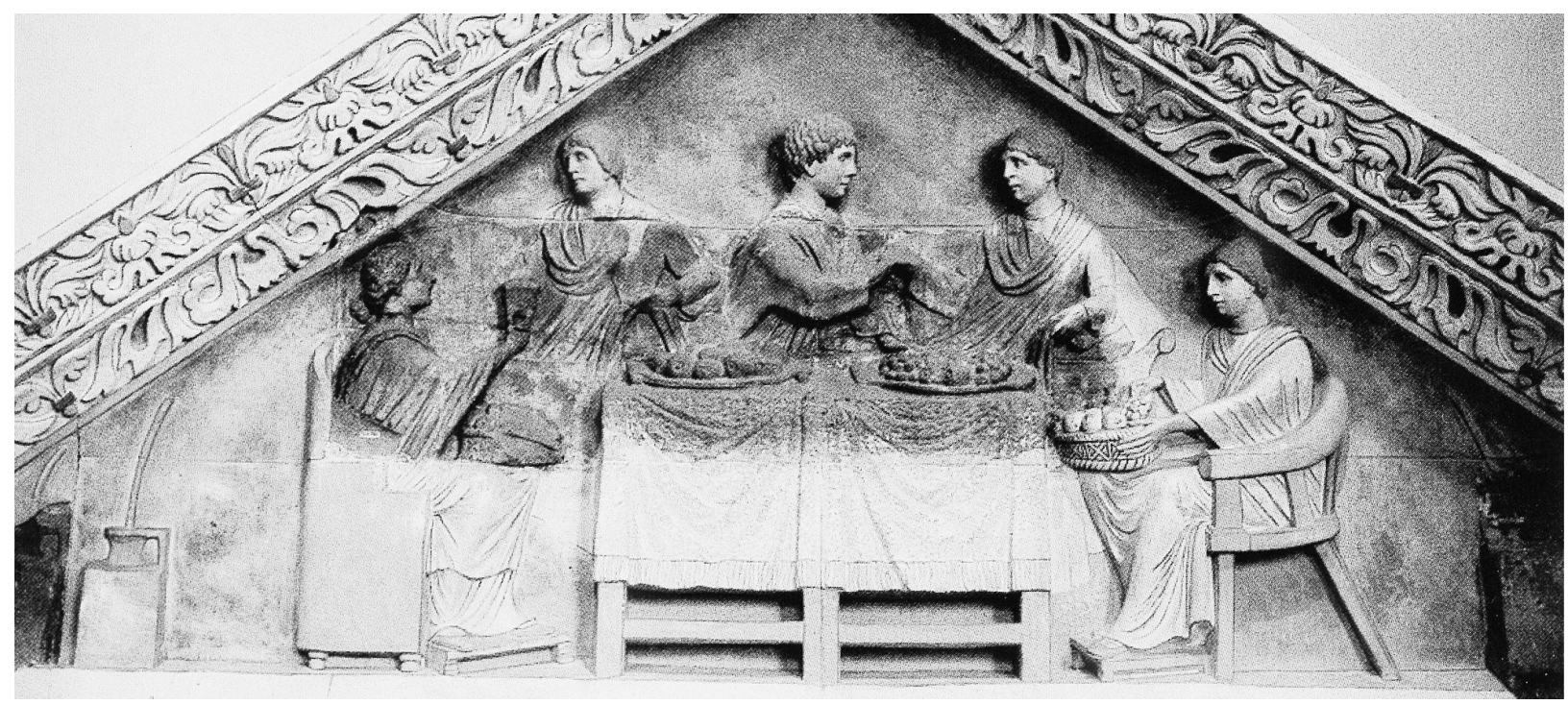

Abb. 32. Neumagen, Relief, nach Gerlach 2001, Abb. 131 (s. Anm. 86).

\section{Zusammenfassung}

Ziel dieser Arbeit war, eine jüngst bekannt gewordene, in Privatbesitz befindliche Silberkasserolle aus Wieselburg, Niederösterreich, vorzulegen. Das Gefäß trägt eine Weihinschrift an Jupiter und eine Gewichtsangabe. Es handelt sich um einen isolierten Streufund. Ein Jupiterheiligtum ist in der näheren Umgebung der Fundstelle zwar wahrscheinlich, aber bislang nicht lokalisiert.

Bei Silberkasserollen scheint es sich um Einzelanfertigungen zu handeln. Sie sind in ihrer Gestaltung viel freier als Bronzekasserollen und nicht in deren gängige Typologien einzuordnen. Die Datierung der seltenen Silberkasserollen ist außerordentlich schwierig, meist stammen sie aus Hortfunden oder aus reichen germanischen Grabinventaren. Weniger in Gallien, vielmehr im Bereich des Balkans konnten die formal ähnlichsten Gefäße ausgemacht werden. Sie legen eine Datierung der Wieselburger Kasserolle in die 2. Hälfte des 2. Jhs. n. Chr. nahe.

Die antike Bezeichnung von Kasserollen ist nicht gesichert. Der oft in diesem Kontext gebrauchte Begriff patera ist offenbar nicht auf sie $\mathrm{zu}$ beziehen. In der Literatur wird oft die Meinung vertreten, Kasserollen (aber auch Kelle-Sieb-Garnituren) hätten als Weinschöpfer gedient. Dies ist m. E. unwahrscheinlich. Zum eigentlichen Kochgeschirr sind Kasserollen insbesondere wegen ihrer geringen Größe wohl auch nicht zu rechnen. Sie fungierten eher als Ess- und Serviergeschirr. Man brachte in der Küche bereitete Speisen, z.B. Fleisch- oder Fischstücke, darin zu Tisch, wo man sie möglicherweise in Kohlebecken warmgehalten hat. Dort wurde dann daraus gegessen, dies belegt besonders der sog. „Mahlzeitgiebel“ aus Neumagen.

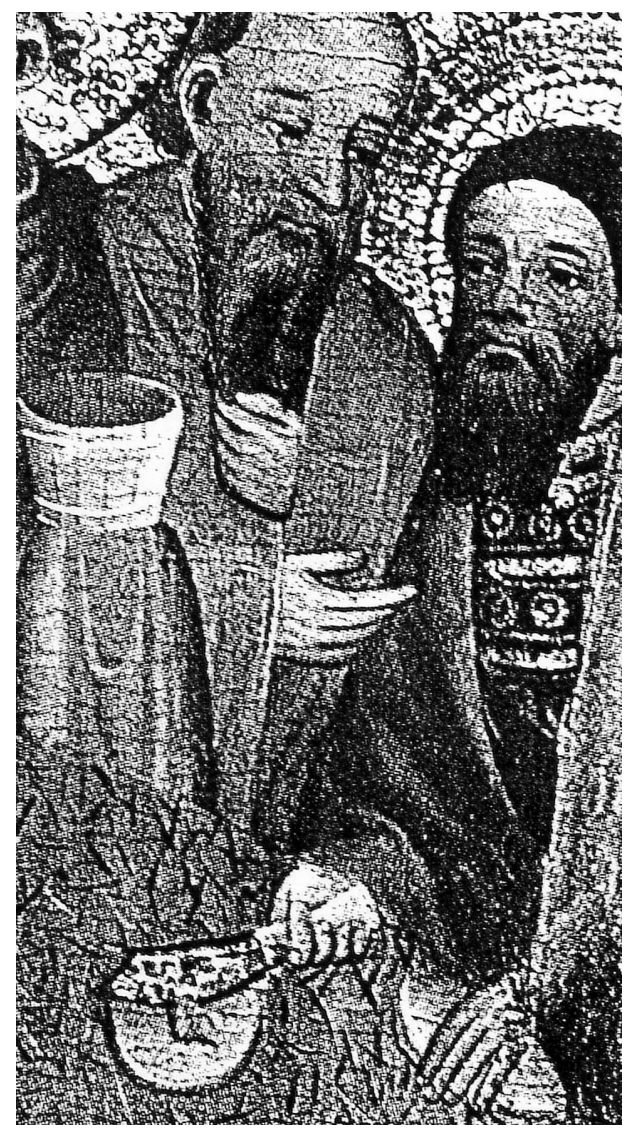

Abb. 33. Altargemälde,

Niedersächsische Landesgalerie Hannover, nach Dexel 1981, Taf. 1 (s. Anm. 104). 
